\title{
THE EMERGENCE OF "SMALL-SCALE" SPORT EVENTS IN "SMALL ISLAND" DEVELOPING STATES: TOWARDS CREATING SUSTAINABLE OUTCOMES FOR ISLAND COMMUNITIES
}

\author{
VASSILIOS ZIAKAS* AND NIKOLAOS BOUKAS† $†$ \\ * Sport \& Health Sciences, University of St Mark \& St John, Plymouth, UK \\ $\dagger$ Center for Sustainable Management of Tourism, Sport and Events (CESMATSE), \\ European University Cyprus, Engomi, Cyprus
}

\begin{abstract}
Although academic literature has examined sport events in urban and rural communities, there is limited research on the forces and dynamics that influence the sustainability of sport events in islands. Cyprus represents a small island developing state with an embryonic event industry, which poses the question whether the emergence of new events can contribute to its sustainable development. The purpose of this study is to examine the impacts of two nascent sport events: the "Limassol Marathon" and the "Tour of Cyprus Cycling Challenge," focusing on their prospects for creating strategic outcomes that can contribute to the sustainability and rejuvenation of Cyprus as a tourism destination. The study employed a triangulation research technique through the application of mixed methods, conducting first semistructured interviews with event organizers, and thereafter a survey examining the perceived experiences of event participants. Findings illustrate the interrelationships of new small-scale events that can amplify their synergistic value by enabling the achievement of multiple purposes. Implications are drawn concerning the synergistic value of small-scale sport events and the strategic processes for creating a range of sustainable event outcomes.
\end{abstract}

Key words: Small-scale events; Marathon; Cycling; Small island states; Sustainability; Community development; Tourism development; Sustainable event outcomes

Introduction

The implementation of events and the nature of their impacts, outcomes, or legacies are inherently linked to the spatial characteristics of the host communities in which they take place (Getz, 2012). Contingent upon the geographic location, size, population, or morphology of an area, events of different types and scales are created or attracted accordingly, which have, in turn, the capacity to project the host community's characteristics and qualities (Boukas, Ziakas, \& Boustras, 2013; Ziakas \& Boukas, 2013; Ziakas, 2013a). Sport events due to their popular appeal have taken a prominent place

Address correspondence to Vassilios Ziakas, Associate Professor in Sport Management, Faculty of Sport \& Health Sciences, University of St Mark \& St John, Derriford Road, Plymouth, PL6 8BH Devon, UK. Tel: +44 [0] 1752636700 ;

Fax: +44 [0] 1752-636820; E-mail: vziakas@marjon.ac.uk 
in the policy agendas of host communities, and are thus constantly employed by large or smaller towns to achieve a range of economic or social benefits (O’Brien \& Chalip, 2008), such as developing tourism (Chalip \& McGuirty, 2004; Dansero \& Puttilli, 2010; Faulkner et al., 2000), building host destination brands (Brown, Chalip, Jago, \& Mules, 2004; Chalip \& Costa, 2005), enhancing destination image (Chalip, Green, \& Hill, 2003; Gibson, Qi, \& Zhang, 2008; Grix, 2012), fostering social capital (Misener \& Mason, 2006; Schulenkorf, Thomson, \& Schlenker, 2011), achieving community development (Kellett, Hede, \& Chalip, 2008; Schulenkorf \& Edwards, 2012; VanWynsberghe, Derom, \& Maurer, 2012), increasing sport participation (Frawley \& Cush, 2011; Girginov \& Hills, 2008; Veal, Toohey, \& Frawley, 2012), and overall, improving a host community's quality of life (Kaplanidou, 2012; Ziakas, 2010). To what extent are the processes for the achievement of positive legacies similar or different across the cities and smaller towns that stage sport events and how does this affect the choice of strategic means to attain intended outcomes?

Given the limited research on the geography of sport (Bale, 2003) and sport events, it is hard to give a thorough answer to the above question. Even harder to find an answer is the case of islands that host sport events, which has received the least research attention. In fact, although academic literature has extensively examined sport events in cities (e.g., Burbank, Andranovich, \& Heying, 2002; Carlsen \& Taylor, 2003; Essex \& Chalkley, 1998; Garcia, 2004; Hiller, 2006; Misener \& Mason, 2008, 2009; Smith, 2012; Ziakas \& Boukas, 2012) and rural communities (e.g., Higham \& Ritchie, 2001; Janiskee \& Drews, 1998; Jones, 2005; Moscardo, 2008; Reid, 2008, 2011; Ziakas \& Costa, 2010a, 2011a), there is a paucity of research on the forces and dynamics that influence the sustainability of sport events in islands. This poses fundamental questions concerning the types of sport events that are more conducive to islands' endogenous development characteristics and the processes that lead to sustainable event outcomes and legacies.

Small islands are more vulnerable to unsustainable development mainly because of their resource scarcity. Thus, they are often found to be overdependent on the tourism industry, catering for the lower end of the mass tourism market, exhausting natural resources, and causing environmental degradation (Bull \& Weed, 1999; Lim \& Patterson, 2008). Even small island states, which have the advantage to devise their own development policies, tend to have overreliance on tourism and foreign capital, hence limiting their sustainable development (Lewis-Cameron \& Roberts, 2010). In this regard, as it has been suggested in the literature, the staging of small-scale sport events constitutes a viable option for enhancing a host community's quality of life and fostering sustainable tourism development within the confines of its carrying resource capacity (Gibson, Kaplanidou, \& Kang, 2012; Higham, 1999; Wilson, 2006; Ziakas, 2013b). To realize this potential in the case of small island states, it is essential to examine the processes and outcomes of event implementations in relation to characteristics and attributes of small-scale sport events that enhance their community-building role as well as the tourism product of a small island state.

Cyprus is a small island developing state that witnesses an embryonic event industry and thus, represents a suitable context for studying the creation and emergence of small-scale sport events and their potential contribution to the sustainable development of the island. The purpose of this study is to examine the impacts of two nascent sport events, the "Limassol Marathon GSO" and the "Tour of Cyprus Cycling Challenge," with a focus on their prospects for creating strategic outcomes that can contribute to the sustainability and rejuvenation of Cyprus as a tourism destination. In so doing, the study identifies the intended outcomes and examines the implementation processes through the event organizers' perspective. It then analyzes the experiential event characteristics based on participants' perceptions to determine whether or not the attributes of both events enable the achievement of sustainable outcomes.

\section{Contextualizing the Emergence of "Small-Scale" Sport Events in "Small Island" Developing States: The Case of Cyprus}

\section{Small Island States and Small-Scale Events: A Sustainable Fit?}

The endogenous characteristics of small islands are similar to those of microstates. According to 
Wilkinson (1989), the term "microstate" is used to explain various forms of political units with population under one million. The term applies both on small islands and continental small states. Conversely, Rich (2008) argues that the lack of a clear definition of microstates produced varied definitions based upon two determinants: population and size. In disentangling this confusion, Rich defines microstates of size $20,000 \mathrm{~km}^{2}$ and less without considering the size of the population. Nevertheless, because several islands are small countries having their own political administration, they could also be qualified as microstates.

Wilkinson (1989) suggests that island microstates "constitute a relatively distinct subset of microstates, which are worthy of study: smaller, many characteristics of Third World countries, and important (and often dominant) tourism sectors" (p. 154). Although many small island economies have higher income per capita than Organization for Economic Cooperation and Development countries (Hampton \& Christensen, 2007) and many belong to the First World according to the World Bank standards (Wilkinson, 1989), there is a tendency for overdependence of microstate islands on tourism. As Craigwell (2007) argues, for small island developing states, tourism is an essential part of their economic activity and thus competitiveness because it is the principal market of the service industries with the potential to contribute both to the economy of the microstates and to the society at large.

The morphology of islands often creates attractive characteristics for tourists. Carlsen and Butler (2011) argue that islands are desirable destinations because of the unique elements that offer to tourists such as the authentic cultural/natural experience and their exceptional scenery. Accordingly, Lewis-Cameron and Roberts (2010) maintain that many small island states capitalize on their natural comparative advantages such as salubrious climate, pristine coral reefs, compelling architectural heritage, a smorgasbord of culinary offerings, rich and vibrant cultures, and friendly and welcoming people to explicitly and deliberately follow tourism as development option.

As Butler (2008) notes, islands in the Mediterranean, Caribbean, and South Pacific are significant destinations. The economic contribution of tourism for small island states often creates challenges for these locations such as monothematic mass tourism, seasonality, and crowdedness. Also, Niles and Baldacchino (2011) note that although islands are projected as places with rich and diverse flora/ fauna at the same moment they face resource deficiency, segregation, and dependency on the rest of the world. Niles and Baldacchino, in explaining this oxymoron phenomenon, support that islands struggle to balance two antithetical purposes: (1) to keep the ecological integrity, and (2) to strive for the economic development and community quality of life, considering also the urgency to preserve the social and spatial characteristics. Consequently, islands confront problems such as climate change and scarcity of resources, while dealing with dependencies on the global economy and on tourism.

Lewis-Cameron and Roberts (2010) argue that for many small island states, tourism development is inextricably dependent on the existence of foreign capital. The natural scenery of the islands attracts many foreign investors but there is always the risk of overdependence on foreign investments. Lewis-Cameron and Roberts (2010) mention that in many cases, the foreign ownership of the tourism superstructure is evident, while local people and residents of the island are on the base of the pyramid regarding ownership and employment. This occurs because most local residents do not have the financial power to support large-scale projects such as hotels. In addition, Carlsen and Butler (2011) note that island tourism development faces a number of challenges such as dependency on external forces, reduction of traditional economic activities, vulnerability in various crises, and isolation. Therefore, it is sufficed to say that if appropriate policies and strategies are not implemented, tourism development in small island developing states threatens sustainable stewardship of their limited resources and sociocultural character (Boukas \& Ziakas, 2013a).

As many islands have been trying to remedy the problems of tourism development, they capitalize on sport tourism and sport events particularly. For example, Malta has developed a range of sport events and activities, including among others diving, yachting, power boating, golf, football, and swimming in order to diversify its tourism product (Bull \& Weed, 1999). Similarly, Cuba offers a 
range of residential coaching camps in elite competitive sports such as athletics, boxing, basketball, volleyball, and gymnastics, and sport events for the general population like golf, marathons, and cycling (Sugden, 2007). Conversely, Cyprus has invested mainly in golf, aspiring to become a reputable international golf destination (Boukas \& Ziakas, 2013b) but without prudently planning for protecting its scarce natural resources (Boukas, Boustras, \& Sinka, 2012). These examples demonstrate two overarching differences for sport event policy in small island developing states, which stem from their small size: on the one hand, small island states do not have large-scale bureaucratic structures and regional divisions, thereby facilitating the coordination of sport policies and event implementations, but on the other hand, they require small-scale interventions that safeguard their scarce resources.

In general, Higham (1999) was the first scholar who recognized the need for host communities to attract or develop sport events that complement their scale, infrastructure, and resource capabilities. According to Higham, small-scale sport events usually operate within existing infrastructures, require minimal investments of public funds, are more manageable in terms of crowding and congestion compared to hallmark events, and can minimize the effects of seasonality. Accordingly, research that was undertaken on the Super 12 Rugby Union competition in New Zealand (Higham \& Hinch, 2002) and in Australia (Ritchie, 2004; Ritchie, Mosedale, \& King, 2002) suggested the potential of this competition to generate domestic and international visitation, entice visitor spending, and contribute towards building destination image and branding. Similarly, Ritchie (2005) examined the dynamics of the New Zealand Masters Games, concluding that they provide an economic boost for the local economy through using infrastructure and providing increased revenues for the food/beverage and retail sectors. Additionally, Wilson (2006) assessed the economic impact of four small-scale swimming events, concluding that they have the potential to generate unequivocal economic benefits to their host communities providing that secondary expenditure opportunities are available. Along the same lines, O'Brien (2007) demonstrated the potential for leverage from a small regional surfing event.
There is a wide range of sport activities that can be staged by small island states in order to attract tourist visitation and achieve community benefits. Among them, running marathons and cycling tours are favorite choices, perhaps because the nature of these sports enables to "tour" participants around core island attractions, hence promoting the identity and image of the island as a tourism destination. In addition, these sport events operate within the existing natural infrastructure and convey social messages that can be easily tied to community building or charitable purposes (Balduck, Maes, \& Buelens, 2011; Berridge, 2012; Bull \& Lovell, 2007; Coghlan, 2012; Filo, Funk, \& O’Brien, 2008; Snelgrove \& Wood, 2010; Sugden, 2007). Nonetheless, the predominant focus of marketing-led research examines merely the economic outcomes that derive from consumer expenditure (e.g., Agrusa, Tanner, \& Lema, 2006; Downward, Lumsdon, \& Weston, 2009; Wicker, Hallmann, \& Zhang, 2012), tourism development (e.g., Bull, 2006; Lamont, 2009; Lamont \& McKay, 2013), and participants' or visitors' experience (e.g., Kruger \& Saayman, 2012; Shipway \& Jones, 2007, 2008), rather than investigating the processes and attributes of marathon and cycling events that create sustainable legacies and foster community development. Within the context of small island states, little is known about the conditions and endogenous spatial characteristics that determine events' appropriateness or sustainable fit with the host island.

Consequently, the potential of small-scale sport events to foster sustainable development in small island states needs to be explored in order for empirically substantiating their value. Given the prominence of the tourism industry and resource scarcity in most small island states, it is imperative that sport event strategies optimize the use of resources in achieving a range of community and tourism benefits synergistically. For this reason, we need to study in concert the community and tourism development prospects of sport events in small island states, which can be affected by their remoteness, excessive dependence on international trade, and a vulnerability to global developments. In addition, small island developing states suffer from a lack of economies of scale, high transportation, and communication costs, as well as costly 
public administration and infrastructure establishment (Lim \& Patterson, 2008).

Therefore, the overreliance of the small island economies on tourism and foreign capital along with the occurrence of unforeseen disasters, exogenous failures of the global financial system, political instability, social unrest, or other crises raise questions about how they can become competitive destinations without forfeiting their natural character and harming their sociocultural fabric in the long term. Cyprus is a typical example of a small island microstate with an unplanned mass tourism tradition that deteriorated its natural environment and quality of life, as well as fragile structural characteristics that diminish its competitiveness in the international arena as global changes occur.

\section{The Case of Cyprus: Unplanned Development and Inflated Outcomes}

The modern history of Cyprus is marked by a tumultuous political context after gaining its independence from Great Britain in 1960. The first years of the new-born state were characterized by severe political unrest between the Greek-Cypriot population and the Turkish-Cypriot minority, creating the fragile foundations that the new state was established upon. The unrest was culminated in 1974 with the coup of military junta orchestrated by Greece and the ensuing Turkish invasion, which resulted in the illegal occupation by Turkey of about $38 \%$ of the island and a never-ending conflict that perpetuates the ethnic-political division of the island.

Although the Turkish invasion shattered the fragile economy of the island, the impoverished local population in the free part of Cyprus managed to recover quickly in economic terms. The so-called "economic miracle" from 1980 to 2008 brought an exponential economic growth and prosperity to the island leading to a service-based economy and a conspicuously consumption-oriented way of life. However, this growth was disproportionately based on a hypertrophic banking system and unplanned tourism development. Mass tourism targeted mostly at British and Scandinavian markets (Ioannides, 1992) and offering sun-based elements or 3 Ss tourism (i.e., sea, sand, and sun) was seen as a panacea for resolving all developmental problems on the island and achieving short-term economic growth (Ioannides, 2001; Sharpley, 2002; Witt, 1991). However, the rapid development of mass tourism has caused severe negative impacts such as seasonality, an unbalanced development on only some coastal areas (Sharpley, 2002), monothematic offerings, and poor service quality (Archontides, 2007) that decreased the competitiveness of the Cypriot tourism product.

Overall, the service-based economic growth yielded inflated revenues and uncontrolled wealth creation without ensuring long-term sustainable development. Consequently, the advent of the global financial crisis in Cyprus caused gradually (from 2009 until 2013) the collapse of the island's economy. As tourism is the cornerstone of the island's economy, the Cypriot administration has sought to improve its tourism industry by diversifying and upgrading its tourism product (Boukas \& Ziakas, 2013a; Ioannides \& Holcomb, 2001). Thus, the development of marines and golf has been employed as a means of targeting upscale tourists and making Cyprus an international up-market destination (Boukas \& Ziakas, 2013b).

In particular, the choice of golf seeks to take advantage of the island's weather, location, and natural scenery, while working together with the real estate industry. However, this ad hoc measure does not take into account the exhaustion of scarce resources (mainly water and land) and the long-term problems that may be created. In fact, Cyprus policy makers fail to appreciate the wider role that sport could have in tourism and community development efforts. Further, the lack of a comprehensive sport development system and adequate facilities, as well as the predominance of football as a policy focus (Kartakoullis, Kriemadis, \& Pouloukas, 2009), do not help in broadening the scope of planning to provide different sports, activities, and events. As a result, there is limited support from local authorities for a range of grassroots sports or sport tourist activities and staging of associated events. Yet, what does not start from government may be initiated by citizens. Thus, in the absence of government support and planning, voluntary groups and individuals appear to organize sport activities to support community goals. Some of these activities 
are so successful that become recurring small-scale events, such as the Paphos International Rally, the Troodos Sports and Fun Festival, the Limassol Marathon, and the Tour of Cyprus Cycling Challenge, which have both tourism and social goals. As the emergence of these events is of voluntary nature, they mirror the attempt of local people to address pressing community (i.e., health, environment, and solidarity) and economic (i.e., tourism) issues in Cyprus and thus eventually improve the quality of life on the island.

\section{Theoretical Underpinnings}

In order to investigate the potential of nascent small-scale sport events to contribute to the sustainable development of Cyprus, the analysis is grounded in the following three theoretical angles: (1) event leveraging, (2) destination capitals, and (3) event portfolio perspective. These theoretical angles provide a robust conceptual base for situating the strategic planning of small-scale sport events in a sustainable framework and envisioning their effective leveraging.

Specifically, the notion of leverage has been introduced by Chalip (2004) to denote those activities, which need to be undertaken around the event itself, and those that seek to maximize the longterm benefits from events. This approach entails a forward, ex ante, and analytic mindset for event planning focusing on why and how intended outcomes can occur, thereby explaining the processes and strategic means that can enable their attainment. From this prism, events should be seen as opportunities for interventions; not interventions in themselves (Chalip, 2004). As O'Brien (2006) suggests, events and their opportunities are merely the seed capital; what hosts do with that capital is the key to realizing sustainable outcomes.

Recognizing events as capital brings forth the need to cross-leverage them with the range of a host community's capitals. Sharpley's (2009) destination capitals approach provides a framework for leveraging the opportunities events create in synergy with the host community's productive assets (i.e., sociocultural, human, environmental, financial, political, and technological) by fostering their interconnectedness in order to generate a flow of sustainable tourism benefits. The challenge is to create the appropriate conditions in which event stakeholders can reach a consensus in formulating leveraging strategies that embed effectively event implementations in the sustainable development of the host community.

An event portfolio perspective dictates the creation of conditions that can enable the incorporation of events into sustainable development strategies. From this standpoint, multiple events of different types and sizes need to be cross-leveraged for achieving multiple purposes that meet the triple bottom line and sustain their outcomes through the implementation of joint event strategies (Ziakas, 2013b). In this vein, synergies between events and their stakeholders can be developed and networks built thereby facilitating efforts for sustainable leverage.

Within this context, the emergence of new smallscale events creates opportunities for capitalizing on their capacity to engender niche markets and meet their needs. However, to realize this potential it is essential to develop knowledge about the processes and means that produce sustainable event outcomes for stakeholders and the impacted communities. On this basis, leveraging can be aligned with the broader policy agenda of host communities. In the case of island destinations, small-scale sport events can be leveraged for achieving multiple purposes such as enriching and diversifying their tourism product or enhancing residents' wellbeing while providing memorable experiences to participants and visitors.

\section{Method}

\section{Research Context}

Running and cycling are novel sports for Cyprus exhibiting among the lowest participation rates across Europe (European Commission, 2010), which is dominated by football (Kartakoullis et al., 2009). The emergence of small-scale marathon and cycling events initiated by some individuals and community groups in the resort city of Limassol attempt to attract public attention and government support by projecting a range of potential benefits these events could bring to the island. From this standpoint, the underlying aim of the study is to examine the potential impacts and sustainability of these sport events by seeking to uncover the 
processes for creating outcomes that can contribute to the rejuvenation of Cyprus as a tourism destination and its sustainable development.

The particular objectives of the study are the following:

- Identify the intended outcomes sought to be obtained from the events relating to the sustainable tourism development of Cyprus.

- Examine the processes that enable event implementations and the attainment of particular outcomes enhancing the sustainable potential of events and the tourism product.

- Analyze the perceptions of event participants about the characteristics and attributes of events that contribute to a gratifying experience.

It should be noted that it is out of the scope of this study to analyze the resident perceptions about the social impact of the marathon and cycling events due to their newness and subsequent unfamiliarity of the local population, which would have yielded premature or impulsive responses. Instead, at this early stage of the events' lifecycle the study focuses on the processes, outcomes, and characteristics through the experiential perceptions of organizers and participants, which can reveal the potential of these events to achieve sustainable outcomes. This study lays the ground for examining resident perceptions as a later stage, thereby comparing and contrasting perceptions, attitudes, and viewpoints of various stakeholders about the social impact of these events, when they will have been crystallized in Cypriot life and calendar.

\section{Profile of Events}

Limassol Marathon GSO (Gymnastikos Syllogos Olympia) is the official marathon of Cyprus, fully accredited by the respective international federation. Its hosting is coordinated voluntarily by the "Athletics Club Olympia" being under the administration of the Cyprus Federation of Amateur Athletics and the Cyprus Sports Organization, which is the island's national governing body. The marathon started in 2007 and has rapidly evolved into an event that attracts international and local participation of about 3,000 people. As event organizers proclaim, the marathon is more than a sport event; it is a celebration of values, social awareness, and solidarity. The event's program, in addition to the marathon race, includes a half marathon, health race, corporate race, and a children/student race. The flat traffic-free route is ideal for all runners and participants to achieve their personal best. The marathon's slogan "Run Along the Waves" represents the experience of running along the beautiful Limassol coastline. Limassol is the second largest city of Cyprus and is famous for its mild weather, long beaches, beautiful trails, nightlife, and hospitality. Molos area on the sea front is the start and finish point of the marathon, combining a route of Limassol's scenery and the Mediterranean Sea. For the greatest part of the race, the athletes have the sea on the south side of the route and a changing environment on the north side, ranging from the city buildings to parks and archaeological sites of 3,000 years of history.

The Tour of Cyprus Cycling Challenge is the only international cycling event in Cyprus. It is a professional multistage endurance "Tour de France" style race and is open to amateurs and competitive cycling riders. The Tour of Cyprus is organized by the voluntary organization named "Podilatokinisi Cyprus Cycling Association" and is independent from the Cyprus Cycling Federation and the Cyprus Sports Organization. The event aims apart from local participation to encourage international cyclists to live their passion outside of their country and enable them to discover new horizons, in terms of both sport and culture. The first Tour of Cyprus was staged in 2005 when a group of local cycling enthusiasts organized a 3-day, 350-km ride on the island. In 2006, the event became part of the annual calendar of the largest bicycling organization in Cyprus. As of 2009, more than 50 local cyclists participated in a 5-day event of $570 \mathrm{~km}$. The 2009 Tour of Cyprus took place under the auspices of the Ministry of Communication and Works while the Cyprus police, the Cyprus Tourism Organization, and a number of municipalities also provided support. The 2010 Tour of Cyprus was open to local and international participants, with over 100 cyclists taking part. The event in each stage takes riders through the beautiful landscape of Cyprus, with sections of the stages climbing into the Troodos mountain area and along a number of coastal routes. There are also sections 
of the Tour that include rides through major cities and picturesque villages.

\section{Data Collection}

A mixed-methodological approach was employed that incorporated the use of both qualitative and quantitative data collection methods. This approach, although it is essentially a triangulation research technique and thus can provide rich as well as robust data (Decrop, 1999; Finn, Elliot-White, \& Walton, 2000), has not been widely applied to the study of sport events.

The qualitative data were collected through semistructured interviews with event organizers in order to elicit their perspectives about the processes that facilitate or constrain the attainment of successful outcomes. Semistructured interviews were employed because they allow more detailed information to be gathered, by providing an opportunity for the interviewer to probe and expand the interviewee's responses (Weiss, 1994; Yin, 2009). In total, four interviews were conducted with the two organizers of each event. The interviews were conducted in the offices of the interviewees and their length was about 1 hour. Questions focused on the objectives of event organizers, the organizational issues that they face, and the perceived event benefits and impacts on Cyprus. Probes were used to elicit detailed responses on the above matters and also whenever clarification was needed.

The quantitative data were collected through a survey of event participants in order to examine their perceived experiences in the events. In doing so, a self-completed questionnaire with 22 questions was distributed to participants after the end of the two aforementioned events, on March 24, 2013 (Limassol Marathon) and March 30, 2013 (Tour of Cyprus), respectively. For the Limassol Marathon, researchers randomly distributed the questionnaires at the finish point of the marathon, requesting from participants to return them within 2 weeks either by handing them to a contact person (local participants) or posting them in a self-addressed envelope (overseas participants). For the Tour of Cyprus, researchers distributed the questionnaires to all participants attending the final technical briefing of the event and collected them at the end of the briefing.
The questionnaire was developed by the two researchers/authors in two languages: Greek and English. A combination of binary, nominal, ordinal, and summated rating scales (7-point and 10-point Likert scales) were used. The questionnaire included three sections: (1) a section about the demographic characteristics of the respondents, (2) a section about the travel characteristics of the respondents, and (3) a section with questions regarding the respondents' rates for a series of event attributes and experiential elements from their participation in the event. The attributes included in the questionnaire were relevant to several dimensions that overall shape event visitors' perceptions such as quality issues, organization issues, experiential factors, motivational determinants, knowledge, interaction, amenities, and facilities. For ensuring the validity of the instrument, pretesting of the questionnaire was applied. The questionnaire was tested for 3 days prior to the implementation of the study. Piloting took place at two training centers by asking in total 14 respondents who had participated in these events last year. Pretesting generated the need for grammar and spelling readjustments and minor changes of the questionnaire's layout. However, these changes did not misquote the meaning of the questionnaire.

Finally, the population of the quantitative research included all those people who participated in the two events during the specific days. The difficulty to determine the exact number of the participants at the fieldwork led to the use of a convenience sample. Specifically, 118 questionnaires were received back from the respondents that participated in Limassol Marathon. From them, only 108 were usable and proceeded to the analysis stage. Similarly, from the 65 questionnaires submitted by the participants of the Tour of Cyprus, only 58 were qualified to be included in the data analysis of the study.

\section{Data Analysis}

All the interviews were recorded and transcribed verbatim in the Greek language. Thereafter the transcripts were translated in English and analyzed manually by employing an inductive and iterative content analysis (Glaser \& Strauss, 1967; Miles \& Huberman, 1994) that revealed the following thematic categories: (1) intended outcomes and 
objectives of event organizers, (2) core processes in management of event organizers, and (3) proclaimed attributes of the events by the organizers. The transcripts were then subjected to a line-by-line analysis for identifying and categorizing emerging subthemes. This thematic analysis indicated a range of interrelated issues that served as a basis for the analysis of quantitative data.

For the quantitative research, nonparametric tests were the most appropriate method of analysis for the objectives of the study, because there was not normal distribution for all variables tested (Bryman \& Cramer, 2001). Frequencies and mean tests were used for the identification of the demographic and travel characteristics of the respondents. Furthermore, chi-square tests were applied for finding out significant differences between the observed and expected values. The level of probability that was adopted in the study was $p=0.05$. The variables shown in the tables with no asterisk indicate no statistical differences and do not have any explanatory value.

\section{Results}

The results are presented by employing a comparative analysis of the two events under study, thereby revealing their interrelationships and discrepancies. First, the event organizers' viewpoints are described with the order that emerged from the interviews. Then the perceptions of participants about their events experience, as answered in the survey, are presented to indicate the perceived processes and outcomes that foster the value of the marathon and cycling events for Cyprus.

\section{The Event Organizers' Perspective}

Although there is not an apparent relationship or collaboration between the marathon and cycling events, hence with them being seemingly unrelated, it appears that these events have identical goals. Specifically, as Table 1 illustrates, the objectives and expected outcomes of both event organizers seek to boost tourism visitation on the island, enhance Cyprus' destination image, increase sport participation in running and cycling, support volunteerism, help change the mentality of Cypriots towards adopting an active lifestyle, promote the health benefits of running and cycling, and overall improve the quality of life for local communities in Cyprus.

In particular, the dual tourism-social orientation of the marathon is demonstrated by the organizers' intention to enhance Limassol's destination image and increase local participation in running:

We want to make the marathon a trademark of Limassol for people abroad. So when people abroad hear about Limassol, they think about the marathon and everyone knows about the Limassol marathon. Also, we promote Limassol as a tourism attraction by projecting through the marathon the coastline, the beaches, the trails, etc.

And,

The marathon helps running to become a part of Limassol people's lives. To learn to participate in sport because running for me is the most fundamental type of sport. You don't need special equipment or facilities, you just wear your uniform and trainers and then you can run. And if you start jogging, you may like it and look for a trainer, a running club, and so on. So the marathon helps in passing across this message and change attitudes towards increasing sport participation.

Similarly, the organizers of the Tour of Cyprus articulate the ostensible tourism objectives of this event:

The Tour of Cyprus targets foreign cyclists - professional and amateur- to visit Cyprus and live their passion here. It enables them to discover new horizons, in terms of both sport and culture. The $90 \%$ of the participants are from abroad, and with more than 150 entries this year from 22 countries, we have achieved to establish the tour as the most important cycling event in the Easter Mediterranean region. So we have put Cyprus on the map of international cycling tourism.

However, they also emphasize that the Tour of Cyprus aims to promote volunteerism and social service in which the event is based upon:

We rely on volunteer work to stage the event since our budget is very limited and the event is complex. From planning and logistics to staffing the registration desk and feed stations, volunteers come to help. We are happy to see new people coming to volunteer especially if you think that 
Table 1

Event Organizers' Objectives and Intended Outcomes

Intended

Outcomes

Limassol Marathon

Tour of Cyprus

Tourism visitation "A significant benefit of the marathon is economic. A lot of runners are coming from abroad - about $35 \%$ of registered participants - and many are from the USA. So these athlete tourists are coming in Cyprus and stay about 5 days and usually bring with them their family or friends who all spend money on the island."

Destination image

"We want to make the marathon a trademark of Limassol for people abroad. So when people abroad hear about Limassol, they think about the marathon and everyone knows about the Limassol marathon. Also, we promote Limassol as a tourism attraction by projecting through the marathon the coastline, the beaches, the trails, etc."

Sport participation "The marathon helps running to become a part of Limassol people's lives. To learn to participate in sport because running for me is the most fundamental type of sport. You don't need special equipment or facilities, you just wear your uniform and trainers and then you can run. And if you start jogging, you may like it and look for a trainer, a running club and so on. So the marathon helps in passing across this message and change attitudes towards increasing sport participation."

Volunteerism

"The organization of an event like the marathon requires the contribution of many local people. From the simple person who will be in the sidewalks to encourage the athlete to the volunteers who will make the registrations, put the bars and tents, prepare the feed stations or the start and finishing lines, etc. So the staging of the marathon is based on volunteer work because without the help of volunteers is impossible to be successful. Basically, the marathon spreads the value of volunteerism to the Limassol community by showing that the unpaid contribution of people for a common cause can benefit the whole community."

Mentality change
"We want all people in Limassol to embrace the marathon and help any way they can. And I think that the marathon can inspire local people. For example, I remember last year one 8-9 y.o. child who was stunned looking the passion of runners who run $42 \mathrm{~km}$ and couldn't believe it. This image will stay forever in this child's mind, instead of having a pop singer as a role model.
"The Tour of Cyprus targets foreign cyclistsprofessional and amateur - to visit Cyprus and live their passion here. It enables them to discover new horizons, in terms of both sport and culture. Of the participants, $90 \%$ are from abroad, and with more than 150 entries this year from 22 countries, we have achieved to establish the tour as the most important cycling event in the Easter Mediterranean region. So we have put Cyprus on the map of international cycling tourism."

"We are promoting Cyprus worldwide as a cycling destination - we want to introduce and 'addict' international cyclists to the island's breathtaking mountain rides and Mediterranean vistas. So the routes of the tour pass through the most beautiful areas of the island and showcase them. Also, images of these areas are shown in the media."

"One of our underlying aims is to promote cycling in Cyprus and encourage participation from local people. This way the number of people participating either in recreational or competitive cycling can hopefully be increased in the near future."

\begin{abstract}
"We rely on volunteer work to stage the event since our budget is very limited and the event is complex. From planning and logistics to staffing the registration desk and feed stations, volunteers come to help. We are happy to see new people coming to volunteer especially if you think that Cyprus does not have volunteerism in its tradition. So the Tour of Cyprus does promote social service, volunteering, and philanthropy, particularly among young people.”
\end{abstract}

"The Tour of Cyprus promotes the use of bicycle on the island. Cycling is not very popular in local culture and there is a need to change attitudes and way of thinking and living. So far there is an impressive increase of bicycle sales in Cyprus and the use of the bicycle is mainly for recreational purposes. We believe this will also lead to an increase in competitive cycling participation in the near future. 
Table 1 (continued)

\begin{tabular}{|c|c|c|}
\hline $\begin{array}{l}\text { Intended } \\
\text { Outcomes }\end{array}$ & Limassol Marathon & Tour of Cyprus \\
\hline & $\begin{array}{l}\text { So the marathon provides other role models, it } \\
\text { gives another vision, direction and goals to pursue, } \\
\text { instead of sitting home, watching television and } \\
\text { admiring the pop idols. Also, the marathon by pro- } \\
\text { viding the opportunity for children to participate in } \\
\text { the } 1 \mathrm{~km} \text {, it changes their mindset and encourages } \\
\text { them get involved in sports. And I think that this } \\
\text { mindset has already started to change in Limassol, } \\
\text { where you see more and more people running in } \\
\text { the streets." }\end{array}$ & $\begin{array}{l}\text { The Tour of Cyprus in this regard helps to } \\
\text { heighten awareness on the island of the ecolog- } \\
\text { ical, economic and health benefits of cycling. } \\
\text { This can be easier done by targeting young } \\
\text { people and have them partaking in a beautiful, } \\
\text { ambitious, and sporting/social event." }\end{array}$ \\
\hline Health promotion & $\begin{array}{l}\text { "We named the } 10 \mathrm{~km} \text { course as a 'Health Race' in } \\
\text { order to promote the importance of running for } \\
\text { the health of people and invite them to participate } \\
\text { and change their lifestyle. Also, by having little } \\
\text { children participating in the marathon we influ- } \\
\text { ence them to start running, come closer to sports, } \\
\text { and adopt a more active way of living when they } \\
\text { grow up." }\end{array}$ & $\begin{array}{l}\text { "The health benefits of cycling as a physi- } \\
\text { cal activity that leads to active living are not } \\
\text { yet well-known in Cyprus. From our side, } \\
\text { we encourage locals to leave the car and } \\
\text { ride the bicycle for exercise, transportation, } \\
\text { and relaxation. For this reason, we also have } \\
\text { the Fun Group for recreational cyclists to } \\
\text { spread the message that cycling is a healthy } \\
\text { recreational activity." }\end{array}$ \\
\hline Quality of life & $\begin{array}{l}\text { "I see many [local] people who run the } 5 \mathrm{~km} \text { race } \\
\text { last year, that now have been registered in the } 10 \\
\mathrm{~km} \text {. Also, I know one marathon runner who started } \\
\text { to train people here in Limassol a couple of years } \\
\text { ago, he had } 2 \text { athletes the first year and now he has } \\
\text { over } 30 \text {. Another example is a } 60 \text { y.o. man who was } \\
\text { registered last year in a running club and this year } \\
\text { he will run his first ever marathon in Limassol. So } \\
\text { it is never too late and I think that the marathon has } \\
\text { an impact on Limassol, people start participating in } \\
\text { running and try to improve themselves, which is a } \\
\text { contribution to the city's quality of life." }\end{array}$ & $\begin{array}{l}\text { "We work closely with the Ministry of Transpor- } \\
\text { tation and the police to ensure the safe staging } \\
\text { of the event. So we try to lobby and draw } \\
\text { attention to the need for increased road safety } \\
\text { and for 'share the road' programs in Cyprus. } \\
\text { Similarly, we are promoting charity organiza- } \\
\text { tions in raising funds for their noble goals that } \\
\text { can help the community." }\end{array}$ \\
\hline
\end{tabular}

Cyprus does not have volunteerism in its tradition. So the Tour of Cyprus does promote social service, volunteering, and philanthropy, particularly among young people.

Likewise, the organizers of both events identified the same core management processes that are essential for the successful staging of events. As Table 2 shows, these processes include the timely scheduling of events, the efforts to attract funding, the events programming, the existence of interorganizational support, the acquired experience in know-how and logistics, the events promotion, and the aspect of cocreation with many participants getting involved in the organization of both events. The scheduling of both events at the end of March takes advantage of the good weather conditions, introducing visitors to the beginning of the tourist season. Both events receive limited financial assistance from the government and their main source of funding is from sponsorships and participants' registration.

A basic difference between the two events is that the marathon appears to have a more targeted program attracting different market segments or groups of people (i.e., children and parents, students, company employees, recreational runners, professional runners). As noted:

In order to encourage local people to participate in the marathon and make it more popular, we created different races in the marathon. One is for children and students, which is $1 \mathrm{~km}$. The corporate race of $5 \mathrm{~km}$ is for groups from local companies and we have more than 40 companies participating. One level up is the $10 \mathrm{~K}$ Heath Race, which is for 
Table 2

Event Organizers' Perceived Core Management Processes

\begin{tabular}{|c|c|c|}
\hline Core Processes & Limassol Marathon & Tour of Cyprus \\
\hline Scheduling & $\begin{array}{l}\text { "The marathon is scheduled in March because } \\
\text { we would like to attract athletes from Northern } \\
\text { countries who try to qualify for the renowned } \\
\text { marathons in the world and they need to make } \\
\text { a good time. As in March the weather is really } \\
\text { good in Cyprus, this is perfect for athletes to } \\
\text { come here train and participate in the marathon at } \\
\text { a time when it is difficult to do that in their home } \\
\text { countries because of the cold weather." }\end{array}$ & $\begin{array}{l}\text { "March is a little before the beginning of } \\
\text { the tourist season and the rates of hotels are } \\
\text { cheaper. The weather is sunny and pleasant, } \\
\text { not hot, not cold. So this is the best period } \\
\text { to schedule the event and bring cyclists } \\
\text { from abroad to train and compete on the } \\
\text { pleasant conditions of the island at an } \\
\text { affordable price." }\end{array}$ \\
\hline
\end{tabular}

Funding

Programming

Interorganizational support

Know-how and logistics
"We don't have public funding. The expenses and overall cost of the marathon are covered mainly from sponsorships and athlete registrations."

"In order to encourage local people to participate in the marathon and make it more popular, we created different races in the marathon. One is for children and students, which is $1 \mathrm{~km}$. The corporate race of $5 \mathrm{~km}$ is for groups from local companies and we have more than 40 companies participating. One level up is the $10 \mathrm{~K}$ Heath Race, which is for everyone who runs to stay fit. And then we have the half-marathon and of course the full marathon for athletes."

"The Gymnastic Club Olympia, the Limassol municipality, the Limassol Chamber of Commerce, and the Limassol Corporation of Tourism Development are the coorganizers of the marathon. We have very good relationships with all the [local] running clubs that help us stage the event, and the police and the army, which help in closing the roads and providing safety. Also, the schools and volunteer clubs send volunteers to the event. So there is enough support from many agencies."

"We didn't have any experience in the organization of a marathon here in Cyprus. So we had to travel and attend other marathons abroad and ask for help from foreign experts. The logistics of such an event are far too many. First of all, to close a road for $42 \mathrm{~km}$ and monitor the safety of the course for all runners in this whole distance requires a lot of attention. Also, it is registrations, the time-taking, the first aid, etc. We have made mistakes in the beginning but we are learning and I think we are in a very good level now."
"The cost of the event is compensated by athlete registrations, sponsors, an EU project, the Youth Organization of Cyprus, and the Ministry of Transportation. Sometimes the Cyprus Tourism Organization and the Cyprus Sports Organization might help but with different amounts and very late."

"We designed the event for two groups. Group A that is the Racing Group and Group B or otherwise the Fun Group. Group A ride includes certain long timetaking sections and only road bikes can be used. Group B riders do the same routes with lower speeds and no time-taking sections. Group B riders have the option to complete as many stages or distance as they wish or feel fit. The measure here is not how a strong rider you are but your determination to challenge yourself. Group B can use any type of bike."

"The event is being supported by various government and semigovernment departments, a great number of municipalities and communities, charitable and philanthropy organizations, and private corporations, as well as the Cyprus police."

"This kind of event has very complicated logistics because it is a multi-stage event. Also, the safety escorting of cyclists by marshals, police and ambulances for a lot of distance is complex as the escorts need to move slowly with their cars and be vigilant all the time to respond to any problem occurring to cyclists." 
Table 2 (continued)

\begin{tabular}{|c|c|c|}
\hline Core Processes & Limassol Marathon & Tour of Cyprus \\
\hline Promotion & $\begin{array}{l}\text { "We use mainly the social media such as Face- } \\
\text { book to promote the marathon. Also, we work } \\
\text { with tour operators to promote the marathon } \\
\text { abroad, while within Cyprus we promote it } \\
\text { through our sponsors. For example, a TV network } \\
\text { that sponsors us will show a promotional pro- } \\
\text { gram about the marathon." }\end{array}$ & $\begin{array}{l}\text { "Our main promoters are our sponsors such } \\
\text { as media and bicycle stores, journalists who } \\
\text { write about us in international magazines, } \\
\text { and the network of cycling organizations } \\
\text { across Europe that inform their registered } \\
\text { cyclists about the Tour of Cyprus." }\end{array}$ \\
\hline Cocreation & $\begin{array}{l}\text { "In essence, the Limassol marathon is its people, } \\
\text { the athletes participating, and the community } \\
\text { supporting it. We [organizing committee] are not } \\
\text { alienated from the people, we don't see the ath- } \\
\text { letes as clients as it happens in well-known mara- } \\
\text { thons. On the contrary, we see the athletes as part } \\
\text { of the marathon's organization. For example, the } \\
\text { running clubs provide equipment and staff and } \\
\text { promote through their networks the marathon. So } \\
\text { it's a different thing to have the athletes helping } \\
\text { in the staging before and after the event from } \\
\text { simply coming to run. They become coorganizers } \\
\text { and care about the event." }\end{array}$ & $\begin{array}{l}\text { "We get a lot of help from participating } \\
\text { cyclists in terms of ideas and suggestions } \\
\text { for improvements. We emphasize that the } \\
\text { participants are what makes the event great } \\
\text { and we welcome their contribution. Some } \\
\text { help with the promotion, the logistics, the } \\
\text { routes and technical details. Without them } \\
\text { it would not have been possible to stage } \\
\text { the event because we don't have enough } \\
\text { money and staff. So we see the participants } \\
\text { as partners. This makes the Tour of Cyprus } \\
\text { a truly cooperative event, a product of all } \\
\text { members' effort and teamwork." }\end{array}$ \\
\hline
\end{tabular}

everyone who runs to stay fit. And then we have the half marathon and of course the full marathon for athletes.

Moreover, the marathon has a wider support from different community organizations. These two aspects enable the marathon to attract a much larger number of participants. Due to the lack of experience and know-how in event management for these new sports in Cyprus both events have problems with the organization and logistics, which gets improved year by year. For example, the event organizers of the marathon mentioned:

We didn't have any experience in the organization of a marathon here in Cyprus. So we had to travel and attend other marathons abroad and ask for help from foreign experts. The logistics of such an event are far too many. First of all, to close a road for $42 \mathrm{~km}$ and monitor the safety of the course for all runners in this whole distance requires a lot of attention. Also, it is registrations, the time taking, the first aid, etc. We have made mistakes in the beginning but we are learning and I think we are in a very good level now.

Finally, due to their limited resources both events rely on sponsors and social networks for their promotion and to a great extent are products of cocreation because they receive assistance from participants (and other stakeholders) on their organizing. Specifically, as the organizers of the Tour of Cyprus pointed out:

Our main promoters are our sponsors such as media and bicycle stores, journalists who write about us in international magazines, and the network of cycling organizations across Europe that inform their registered cyclists about the Tour of Cyprus.

And,

We get a lot of help from participating cyclists in terms of ideas and suggestions for improvements. We emphasize that the participants are what makes the event great and we welcome their contribution. Some help with the promotion, the logistics, the routes, and technical details. Without them it would not have been possible to stage the event because we don't have enough money and staff. So we see the participants as partners. This makes the Tour of Cyprus a truly cooperative event, a product of all members' effort and teamwork.

While this assistance has been necessary in the first place, as both events have been initiated from volunteering individuals with scarce resources and limited public interest, the cocreation is an emerging process that can make the events more appealing and inviting by reinforcing a sense of belongingness for participants. 
Table 3

Event Organizers' Self-Proclaimed Attributes and Characteristics

\begin{tabular}{lll}
\hline Proclaimed Attributes & \multicolumn{1}{c}{ Limassol Marathon } & \multicolumn{1}{c}{ Tour of Cyprus } \\
\hline Route & "The course of the marathon is of a low & "The 3 stages are different each year. \\
degree of difficulty. It is a flat race and & This year each stage/day is circular and \\
has long straight lines. The greatest part of & towards different orientation every time. \\
the marathon takes place along the coastal & That is, there is a stage towards the \\
side of Limassol. So the course is not only & mountains area north of Limassol, a stage \\
pleasant but also helps athletes to achieve & towards west and finally a stage towards \\
their best and improve their time." & east. Each stage takes riders through the \\
& & $\begin{array}{l}\text { beautiful landscape of Cyprus. There } \\
\text { are also sections of the Tour that include } \\
\text { rides through major cities and pictur- } \\
\end{array}$ \\
& esque villages."
\end{tabular}

Weather

Natural scenery

Cultural heritage

Camaraderie

Relationship building
"The weather is sunny and warm here when in Northern and Western Europe is still very cold. So it is very pleasant for everyone to come and run in the Limassol marathon."

"The unique characteristic of the marathon is that it takes place along the coastal road of greater Limassol, thus providing athletes with the opportunity to run along the coastline and enjoy its beauty. To emphasize that our motto is 'Run along the Waves.' This is in contrast with most marathons in the world, which take place in urban centers."

"The course of the marathon is connected with the history of Limassol. For example, it passes nearby ancient Amathus and the historical center of Limassol, projecting hence the history of the city."

"There is a feeling of friendship we try to create through the marathon. For example, the corporate race helps companies to bond their employees since they participate in groups. Also, we consider all athletes and volunteers part of the event's organizing and help each other. We become friends. So the marathon is not simply about competition; it is more about a celebration of athleticism and friendship."

"We are not impersonal as organizers providing only a service to athlete customers. All the athletes know us with our first names and we have a bond with many athletes who contact us all year long to ask how we are doing. Our relationship does not stop with the end of the event. There are some running clubs coming for the 4 th time to the marathon, which is not common to run every year in the same marathon. Some runners who are coming for the first time, they get surprised when they see the other runners to talk with us."
"The temperate spring weather is our greatest selling point. International cyclists are looking for warm destinations to train and compete. That is what they can find in Cyprus right after the cold winter."

"We choose every year stage routes that combine the beautiful landscapes and the natural characteristics of the island like forests, mountains and coastal areas. We want the cyclists to deeply experience the natural environment of Cyprus."

"We organize welcome events along with locals in the villages through which the Tour of Cyprus passes so that the cyclists have the opportunity to experience the local culture such as food and music."

"The cyclists compete in groups and help each other, the more experienced give advice to new cyclists and so on. Many participants tell us that they were very pleased to talk to people from around Europe and different countries. So they make friendships and the event provides an opportunity for cyclists from all over Europe and Middle East to socialize and make friends."

"Many cyclists promise that they will come to participate again next year. They thank us for a great cycling experience in Cyprus filled with wonderful memories. We stay in touch with them throughout the year and keep them informed about the preparations of the event. We are happy to see them again next year and have fun together in the tour. We are like a big family, a family that is always open to accept new members." 
Table 3 (continued)

\begin{tabular}{lll}
\hline Proclaimed Attributes & \multicolumn{1}{c}{ Limassol Marathon } & \multicolumn{1}{c}{ Tour of Cyprus } \\
\hline Local hospitality & "We organize a party for the foreign & "The Tour of Cyprus enables participants \\
athletes where they can have the chance to & and spectators to appreciate the beauty, \\
experience the Cypriot hospitality. More & $\begin{array}{l}\text { cuisine and hospitality of Cyprus. The } \\
\text { importantly, I think that the cheering and } \\
\text { routes of the stages and the welcome } \\
\text { admiration the athletes get from the many } \\
\text { events in the villages are all designed to } \\
\text { local people attending the event, it is a } \\
\text { warm welcome on the island of Cyprus." }\end{array}$ & $\begin{array}{l}\text { project the hospitable environment and } \\
\text { culture of Cyprus." }\end{array}$ \\
\hline
\end{tabular}

In a similar vein, the organizers of both events proclaim the same competitive attributes of the events, which are rooted in the spatial, morphological, and cultural characteristics of Cyprus used to promote the island as a tourism destination. As shown in Table 3, the proclaimed event attributes include the route of events in the landscape of Cyprus, where participants can enjoy the pleasant weather, the beautiful natural scenery, and the cultural heritage of the island. For example, the organizers of the Tour of Cyprus emphasized the incorporation of the island's cultural heritage into the event: "We organize welcome events along with locals in the villages through which the Tour of Cyprus passes so that the cyclists have the opportunity to experience the local culture such as food and music."

Furthermore, according to event organizers, participants have the opportunity to experience the camaraderie, the relationship building, and the local hospitality through the ancillary activities offered in the events. Specifically, the organizers of the marathon mentioned about the event's camaraderie and relationship-building attributes respectively:

There is a feeling of friendship we try to create through the marathon. For example, the corporate race helps companies to bond their employees since they participate in groups. Also, we consider all athletes and volunteers part of the event's organizing and help each other. We become friends. So the marathon is not simply about competition; it is more about a celebration of athleticism and friendship.

And,

We are not impersonal as organizers providing only a service to athlete customers. All the athletes know us with our first names and we have a bond with many athletes who contact us all year long to ask how we are doing. Our relationship does not stop with the end of the event. There are some running clubs coming for the 4th time to the marathon, which is not common to run every year in the same marathon. Some runners who are coming for the first time, they get surprised when they see the other runners to talk with us.

Along the same lines, the organizers of the Tour of Cyprus highlight the opportunity for participants to experience the local hospitality through the event:

The Tour of Cyprus enables participants and spectators to appreciate the beauty, cuisine, and hospitality of Cyprus. The routes of the stages and the welcome events in the villages are all designed to project the hospitable environment and culture of Cyprus.

Overall, the organizers of both events appear to have the same goals, focus on the same management processes, though with some discrepancies on the level of success, and promote the same competitive attributes of their events, as summarized in Table 4. The perspectives of event organizers are based on the potential of running and cycling to become popular for the local population in the long run and promote norms of sustainability and active living. At the same moment, the events incorporate in their mission the destination characteristics of Cyprus and attract participants from abroad, thereby promoting the island as a tourism destination. The events face the same problems, mainly the lack of funding, insufficient know-how, and limited government support, which threaten the attainment of expected outcomes and their sustainability.

\section{The Event Participants' Perceptions}

Profile of Respondents. Tables 5 and 6 present the demographic and travel characteristics of the respondents for both events. 
Table 4

Summary of Event Organizers' Objectives and Perceptions

\begin{tabular}{lll}
\hline Intended Outcomes & \multicolumn{1}{c}{ Core Processes } & Proclaimed Attributes \\
\hline Tourism visitation & Scheduling & Route \\
Destination image & Funding & Weather \\
Sport participation & Programming & Natural scenery \\
Volunteerism & Interorganizational support & Cultural heritage \\
Mentality change & Know-how and logistics & Camaraderie \\
Health promotion & Promotion & Relationship building \\
Quality of life & Cocreation & Local hospitality \\
\hline
\end{tabular}

Participants' Experience in the Events. In order to examine the participants' experience, respondents were asked to rate a series of statements (13 items) that demonstrate their perceived value in the events (13 items), in a 7-point Likert scale ( $1=$ strongly disagree to $7=$ strongly agree). Table 7 illustrates the number of the respondents who replied (n), the mean score of each item, as well as the $\chi^{2}$ and significance value (p), respectively.

For the Limassol Marathon, all elements indicate significant difference. Respondents perceived as the most important elements that shaped their experience during the event, the "good value for money" (6.13), the "friendliness of staff" (6.10), the "improved image of Limassol" (6.07), and "well-staged event" (6.06), indicating that organizational issues and image were considered as determinants of positive experience. All these elements were rated with strongly agree. On the other hand, elements with lower rating were the "reflection of new ideas coming to mind" (5.23), the "acquisition of new knowledge" (5.23) and the "feeling emotionally charged" (5.44). These elements received rating close to neither, indicating that experiential and emotional elements were not met adequately in the specific event.

Likewise, for the Tour of Cyprus, all the variables indicate significant difference. As with the Limassol Marathon, for this event, it was found out that the "friendliness of staff" (6.14) also appeared in the top elements and specifically was rated as the element with the most important score in terms of agreement. This demonstrates that the "human factor" of the event contributed to their positive experience. Additionally, in contrast to the marathon, here emotional aspects such as "felt excitement" (6.09) and "experienced new things" (6.09) were rated at the top in regards to the experience of participants. Generally, the Tour of Cyprus offered better emotional experiences to the participants. On the other hand, characteristics with lower scores are "the value for money of food and drink" (4.52), the well-staged event" (4.81), and the "reflection of new ideas came to mind" (4.86). In contrast to the Limassol Marathon, the Tour of Cyprus had significant problems in its staging and organization (e.g., lack of funding and support from Cyprus Cycling Federation, limited manpower, etc.). Finally, the lack of new ideas coming to mind appeared to be at the bottom places in the rating of both events.

Future Visit and Recommendation. Table 7 also presents two statements regarding the future (repeat) visit to the events as well as the recommendation of the events to family/friends. For these statements, respondents were requested to rate their agreement in a 10-point Likert scale $(1=$ not at all likely to $10=$ very likely). For both statements in the two events $p$ values indicated significant difference.

Therefore, for the Limassol Marathon respondents indicated that there is a large possibility for them to visit the marathon again in the future $(8.25 / 10)$, while they will also recommend the event to others $(8.66 / 10)$, indicating a positive experience and satisfaction from the marathon, overall. However, this does not happen for the case of the Tour of Cyprus. For this event, respondents indicated lower values for both statements. Specifically, participants stated for this event that it is somehow likely to visit the event again in the future $(6.95 / 10)$, while they will probably recommend the 
Table 5

Demographic Characteristics

\begin{tabular}{|c|c|c|}
\hline Characteristics/Categories & $\begin{array}{l}\text { Limassol Marathon } \\
(n=108)[n(\%)]\end{array}$ & $\begin{array}{l}\text { Tour of Cyprus } \\
(n=58)[n(\%)]\end{array}$ \\
\hline \multicolumn{3}{|l|}{ Age } \\
\hline 15 or younger & $12(11.1 \%)$ & $2(3.4 \%)$ \\
\hline $16-19$ & $22(20.4 \%)$ & $11(19.0 \%)$ \\
\hline $20-29$ & $32(29.6 \%)$ & $32(55.2 \%)$ \\
\hline $30-39$ & $27(25.0 \%)$ & $8(13.8 \%)$ \\
\hline $40-49$ & $11(10.2 \%)$ & $4(6.9 \%)$ \\
\hline $50-59$ & $2(1.9 \%)$ & $1(1.7 \%)$ \\
\hline 60 or over & $2(1.9 \%)$ & $2(3.4 \%)$ \\
\hline \multicolumn{3}{|l|}{ Gender } \\
\hline Male & $91(84.3 \%)$ & $46(79.3 \%)$ \\
\hline Female & $17(15.7 \%)$ & $12(20.7 \%)$ \\
\hline \multicolumn{3}{|l|}{ Country of origin } \\
\hline Cyprus & $67(62.0 \%)$ & $15(25.9 \%)$ \\
\hline United Arabic Emirates & $17(15.7 \%)$ & - \\
\hline Canada & $4(3.7 \%)$ & - \\
\hline UK & $3(2.8 \%)$ & $27(46.6 \%)$ \\
\hline USA & $3(2.8 \%)$ & - \\
\hline Greece & $3(2.8 \%)$ & - \\
\hline Israel & $3(2.8 \%)$ & $2(3.4 \%)$ \\
\hline Mexico & $2(1.9 \%)$ & - \\
\hline Sweden & $2(1.9 \%)$ & - \\
\hline Hungary & $2(1.9 \%)$ & - \\
\hline Switzerland & $2(1.9 \%)$ & - \\
\hline Russia & - & $14(24.1 \%)$ \\
\hline Malta & - & $2(3.4 \%)$ \\
\hline \multicolumn{3}{|l|}{ Highest educational level } \\
\hline Primary school & $2(1.9 \%)$ & $0(0 \%)$ \\
\hline Secondary school & $17(16.0 \%)$ & $12(20.7 \%)$ \\
\hline Further education & $28(26.4 \%)$ & $6(10.3 \%)$ \\
\hline Higher education (first degree) & $51(48.1 \%)$ & $23(39.7 \%)$ \\
\hline Postgraduate & $8(7.5 \%)$ & $16(27.6 \%)$ \\
\hline \multicolumn{3}{|l|}{ Annual income } \\
\hline$<5,000$ Euro & $28(29.8 \%)$ & $6(11.8 \%)$ \\
\hline $5,001-10,000$ Euro & $2(2.1 \%)$ & $2(3.9 \%)$ \\
\hline 10,001-20,000 Euro & $12(12.8 \%)$ & $12(23.5 \%)$ \\
\hline 20,001-30,000 Euro & $24(25.5 \%)$ & $6(11.8 \%)$ \\
\hline 30,001-40,000 Euro & $19(20.2 \%)$ & $6(11.8 \%)$ \\
\hline 40,001-50,000 Euro & $6(6.4 \%)$ & $6(11.8 \%)$ \\
\hline 50,001-60,000 Euro & - & $2(3.9 \%)$ \\
\hline$>60,000$ Euro & $3(3.2 \%)$ & - \\
\hline \multicolumn{3}{|l|}{ Current (or former) occupation } \\
\hline Student & $48(44.4 \%)$ & $2(3.8 \%)$ \\
\hline Clerical/administration & $17(15.7 \%)$ & $4(7.7 \%)$ \\
\hline Technical professions & $13(12.0 \%)$ & $4(7.7 \%)$ \\
\hline Service and sales personnel & $9(8.3 \%)$ & $2(3.8 \%)$ \\
\hline Director or manager & $8(7.4 \%)$ & $23(44.2 \%)$ \\
\hline Academic professions & - & $4(7.7 \%)$ \\
\hline Other & $13(12.0 \%)$ & $13(25.0 \%)$ \\
\hline
\end{tabular}

event to others $(7.60 / 10)$. It appears that for the Tour of Cyprus, respondents were more skeptical in regards to future visit and recommendation. It is noteworthy to address that the Limassol Marathon has a relatively high percentage of repeat visitors
(42.6\%), indicating that the Marathon as an event has also kept them satisfied in the past. In other words, the findings revealed the direct association between satisfaction of the respondents and repeat visitation at the specific sport event. 
Table 6

Travel Characteristics

\begin{tabular}{|c|c|c|}
\hline Characteristic/Categories & Limassol Marathon $(n=108)$ & Tour of Cyprus $(n=58)$ \\
\hline \multicolumn{3}{|l|}{ First hearing about the event $[n(\%)]$} \\
\hline Family, friends & $34(31.5 \%)$ & $27(46.6 \%)$ \\
\hline Previous visit & $21(19.4 \%)$ & $7(12.1 \%)$ \\
\hline Event website & $8(7.4 \%)$ & $8(13.8 \%)$ \\
\hline Other website & $3(2.8 \%)$ & $8(13.8 \%)$ \\
\hline Event brochure & $5(4.6 \%)$ & \\
\hline Newspaper/magazine & & $4(6.9 \%)$ \\
\hline Social media & $3(2.8 \%)$ & $2(3.4 \%)$ \\
\hline Other & $34(31.5 \%)$ & $2(3.4 \%)$ \\
\hline \multicolumn{3}{|l|}{ Previous visit at the event $[n(\%)]$} \\
\hline No & $62(57.4 \%)$ & $47(81.0 \%)$ \\
\hline Yes & $46(42.6 \%)$ & $11(19.0 \%)$ \\
\hline \multicolumn{3}{|l|}{ Place of stay during the event $[n(\%)]$} \\
\hline At home & $63(58.3 \%)$ & $2(3.4 \%)$ \\
\hline Hotel & $37(34.3 \%)$ & $56(96.6 \%)$ \\
\hline With friends/family & $8(7.4 \%)$ & - \\
\hline \multicolumn{3}{|l|}{ Importance of the event for visiting Limassol $[n(\%)]$} \\
\hline Only reason for visiting this destination & $89(84.8 \%)$ & $33(56.9 \%)$ \\
\hline One of the main reasons for visiting this destination & $3(2.9 \%)$ & $8(13.8 \%)$ \\
\hline One of several reasons for visiting this destination & $4(3.8 \%)$ & $8(13.8 \%)$ \\
\hline Not a factor, would have visited anyway & $9(8.6 \%)$ & $9(15.5 \%)$ \\
\hline \multicolumn{3}{|l|}{ Average spending per person $[n(€)]$} \\
\hline Admission to the event & $72(31.9 €)$ & $37(182.2 €)$ \\
\hline Merchandise/souvenirs & $16(20.4 €)$ & $16(37.5 €)$ \\
\hline Food and drink & $49(45.3 €)$ & $35(97.1 €)$ \\
\hline Accommodation & $19(135.3 €)$ & $20(172.5 €)$ \\
\hline Shopping & $13(23.1 €)$ & $14(104.2 €)$ \\
\hline Other & $15(23.1 €)$ & $14(191.4 €)$ \\
\hline Total during the whole event & $93(124.7 €)$ & $35(482.0 €)$ \\
\hline \multicolumn{3}{|l|}{ Attractions visited the last year $[n(\%)]$} \\
\hline Sports match & $48(19.8 \%)$ & $26(16.9 \%)$ \\
\hline Film & $45(18.5 \%)$ & $29(18.8 \%)$ \\
\hline Museum & $40(16.5 \%)$ & $27(17.5 \%)$ \\
\hline Theater & $32(13.2 \%)$ & $22(14.3 \%)$ \\
\hline Theme park & $23(9.5 \%)$ & $17(11.0 \%)$ \\
\hline Pop concert & $19(7.8 \%)$ & $14(9.1 \%)$ \\
\hline Musical & $13(5.3 \%)$ & $6(3.9 \%)$ \\
\hline Ballet & $8(3.3 \%)$ & $4(2.6 \%)$ \\
\hline Opera & $5(2.1 \%)$ & $5(3.2 \%)$ \\
\hline Other & $10(4.1 \%)$ & $4(2.6 \%)$ \\
\hline Total & $243(100.0 \%)$ & $154(100.0 \%)$ \\
\hline \multicolumn{3}{|l|}{ Reasons for participating $[n(\%)]$} \\
\hline I like the event & $56(39.2 \%)$ & $25(26.6 \%)$ \\
\hline Entertainment & $18(12.6 \%)$ & $12(12.8 \%)$ \\
\hline To try something new & $18(12.6 \%)$ & $17(18.1 \%)$ \\
\hline Spend time with friends/family & $17(11.9 \%)$ & $11(11.7 \%)$ \\
\hline Visiting the area & $13(9.1 \%)$ & $12(12.8 \%)$ \\
\hline Special occasion & $3(2.1 \%)$ & $7(7.4 \%)$ \\
\hline To see a specific athlete & $3(2.1 \%)$ & - \\
\hline The overall programme & - & $6(6.4 \%)$ \\
\hline Other & $15(10.5 \%)$ & $4(4.3 \%)$ \\
\hline Total & $143(100.0 \%)$ & $94(100.0 \%)$ \\
\hline \multicolumn{3}{|l|}{ Sources of information used $[n(\%)]$} \\
\hline Previous visit & $27(19.3 \%)$ & $12(13.3 \%)$ \\
\hline Event website & $21(15.0 \%)$ & $30(33.3 \%)$ \\
\hline Other website & $8(5.7 \%)$ & $12(13.3 \%)$ \\
\hline Family, friends & $18(12.9 \%)$ & $12(13.3 \%)$ \\
\hline
\end{tabular}


Table 6 (continued)

\begin{tabular}{lcc}
\hline Characteristic/Categories & Limassol Marathon $(n=108)$ & Tour of Cyprus $(n=58)$ \\
\hline Social media & $17(12.1 \%)$ & $8(8.9 \%)$ \\
Guide book & $16(11.4 \%)$ & - \\
Event brochure & $11(7.9 \%)$ & $8(8.9 \%)$ \\
Tour operator brochure & - & $2(2.2 \%)$ \\
TV/Radio & $3(2.1 \%)$ & - \\
Newspaper/magazine & $2(1.4 \%)$ & - \\
Other & $17(12.1 \%)$ & $6(6.7 \%)$ \\
Total & $140(100.0 \%)$ & $90(100.0 \%)$ \\
Social media $[n(\%)]$ & & $48(64.9 \%)$ \\
Facebook & $85(75.2 \%)$ & $2(2.7 \%)$ \\
MySpace & $5(4.4 \%)$ & $10(13.5 \%)$ \\
Twitter & $23(20.4 \%)$ & $10(13.5 \%)$ \\
Linkedin & - & $4(5.4 \%)$ \\
Other & - & $74(100.0 \%)$ \\
Total & $113(100.0 \%)$ & \\
\hline
\end{tabular}

Table 7

Events Experience of Participants

\begin{tabular}{|c|c|c|c|}
\hline & Mean Score & $\chi^{2}$ & $p$ \\
\hline \multicolumn{4}{|l|}{ Limassol Marathon $(n=108)$} \\
\hline 1. The event was good value for money & 6.13 & 100.056 & $0.00 *$ \\
\hline 2. The staff were friendly and helpful & 6.10 & 102.111 & $0.00^{*}$ \\
\hline 3. This event improved my image of Limassol & 6.07 & 132.852 & $0.00^{*}$ \\
\hline 4. I think the event was well staged & 6.06 & 120.278 & $0.00^{*}$ \\
\hline 5. The food and drink is good value for money & 5.94 & 52.352 & $0.00^{*}$ \\
\hline 6. This event made me feel part of a bigger community & 5.93 & 76.074 & $0.00^{*}$ \\
\hline 7. During the event I felt excited & 5.91 & 90.000 & $0.00^{*}$ \\
\hline 8. I think the event is doing a good job of limiting its environmental impact & 5.90 & 65.444 & $0.00^{*}$ \\
\hline 9. During the event I experienced new things & 5.81 & 117.037 & $0.00^{*}$ \\
\hline 10. During the event I experienced something unique & 5.81 & 77.500 & $0.00^{*}$ \\
\hline 11. During the event I felt emotionally charged & 5.44 & 63.111 & $0.00^{*}$ \\
\hline 12. During the event I acquired new knowledge & 5.23 & 86.370 & $0.00^{*}$ \\
\hline 13. During the event I reflected on new ideas that came to mind & 5.23 & 61.630 & $0.00^{*}$ \\
\hline \multicolumn{4}{|l|}{ Tour of Cyprus $(n=58)$} \\
\hline 1. The staff were friendly and helpful & 6.14 & 55.172 & $0.00^{*}$ \\
\hline 2. During the event I felt excited & 6.09 & 25.621 & $0.00^{*}$ \\
\hline 3. During the event I experienced new things & 6.09 & 63.862 & $0.00^{*}$ \\
\hline 4. I think the event is doing a good job of limiting its environmental impact & 5.36 & 23.724 & $0.00^{*}$ \\
\hline 5. The event was good value for money & 5.34 & 26.000 & $0.00^{*}$ \\
\hline 6. This event made me feel part of a bigger community & 5.34 & 64.069 & $0.00^{*}$ \\
\hline 7. During the event I felt emotionally charged & 5.22 & 18.759 & $0.00^{*}$ \\
\hline 8. This event improved my image of Limassol & 5.21 & 35.241 & $0.00^{*}$ \\
\hline 9. During the event I acquired new knowledge & 5.16 & 22.483 & $0.00^{*}$ \\
\hline 10. During the event I experienced something unique & 4.93 & 30.103 & $0.00^{*}$ \\
\hline 11. During the event I reflected on new ideas that came to mind & 4.86 & 26.690 & $0.00^{*}$ \\
\hline 12. I think the event was well staged & 4.81 & 14.655 & $0.02 *$ \\
\hline 13. The food and drink is good value for money & 4.52 & 18.517 & $0.01^{*}$ \\
\hline \multicolumn{4}{|l|}{ Limassol Marathon } \\
\hline How likely are you to visit this event again in the future & 8.28 & 153.926 & $0.00^{*}$ \\
\hline How likely are you to recommend this event to family/friends & 8.66 & 174.667 & $0.00^{*}$ \\
\hline \multicolumn{4}{|l|}{ Tour of Cyprus } \\
\hline How likely are you to visit this event again in the future & 6.95 & 17.552 & $0.00^{*}$ \\
\hline How likely are you to recommend this event to family/friends & 7.60 & 32.310 & $0.01^{*}$ \\
\hline
\end{tabular}

*Significant difference. 
Importance of Event Attributes. In line with the previous analysis, respondents were asked to rate 12 event attributes after their participation in the events, in order to find out the importance of each one and contribution to their perceived experience. For doing so, respondents rated these attributes in a 7-point Likert scale $(1=$ strongly disagree to $7=$ strongly agree). Table 8 presents the mean scores and $\chi^{2}$ values for each attribute. All the scores for both events indicated significant difference, except from the attribute "amenities and facilities" in the Tour of Cyprus, for which the $\mathrm{p}$ value showed no significance $(p=0.89)$.

For the case of Limassol Marathon, the attributes with the greatest scores were the "environmental friendly sport activity" (6.31), the "natural scenery" (6.19), the "active involvement in sport activities" (6.18), and the "pleasant weather" (6.17). Based on these scores, these attributes were those features of Limassol Marathon that were considered as important (after participating in the event). On the other hand, attributes such as the "opportunity to purchase local products/services" (5.04), "learn the culture of Limassol/Cyprus" (5.64), and "combination with other tourist activities" (5.65) were rated as the least important. The marathon was not considered as a means to buy local products, to know better the place, and to participate in other tourist activities.

As with the Limassol Marathon, the most important attributes in the Tour of Cyprus were the "active involvement in sport activities" (6.28), the "natural scenery" (6.19), the "pleasant weather" (6.16), and the "environmental friendly sport activity" (6.00). It appears that for both events the respondents rated as the most important attributes those that contribute to the overall environment of the destination and the aesthetically beautiful natural scenery, and that provide active involvement in sport activities in good weather conditions. On the other hand, attributes such as "opportunity to purchase local products/ services" (4.43), "learn the culture of Limassol/ Cyprus" (4.50), and "combination with other tourist activities" (4.93), as with the case of the marathon, were perceived as the least important. This

Table 8

Importance of Event Attributes After Participation

\begin{tabular}{lccc}
\hline & Mean Score & $\chi^{2}$ & $p$ \\
\hline Limassol Marathon $(\boldsymbol{n}=\mathbf{1 0 8})$ & & & \\
1. Environmental friendly sport activity & 6.31 & 92.833 & $0.00^{*}$ \\
2. Natural scenery & 6.19 & 154.63 & $0.00^{*}$ \\
3. Active involvement in sport activities & 6.18 & 95.981 & $0.00^{*}$ \\
4. Pleasant weather & 6.17 & 96.167 & $0.00^{*}$ \\
5. Connection with the natural environment & 5.98 & 52.926 & $0.00^{*}$ \\
6. Inviting local community & 5.81 & 84.500 & $0.00^{*}$ \\
7. Amenities and facilities & 5.80 & 71.019 & $0.00^{*}$ \\
8. Quality of event services & 5.80 & 65.185 & $0.00^{*}$ \\
9. Social interaction & 5.76 & 52.444 & $0.00^{*}$ \\
10. Combination with other tourist activities & 5.65 & 65.963 & $0.00^{*}$ \\
11. Learn the culture of Limassol/Cyprus & 5.64 & 67.000 & $0.00^{*}$ \\
12. Opportunity to purchase local products/services & 5.04 & 58.574 & $0.00^{*}$ \\
Tour of Cyprus $(\boldsymbol{n}=\mathbf{5 8})$ & & & \\
1. Active involvement in sport activities & 6.28 & 36.207 & $0.00^{*}$ \\
2. Natural scenery & 6.19 & 22.414 & $0.00^{*}$ \\
3. Pleasant weather & 6.16 & 34.241 & $0.00^{*}$ \\
4. Environmental friendly sport activity & 6.00 & 15.655 & $0.00^{*}$ \\
5. Connection with the natural environment & 5.72 & 22.345 & $0.00^{*}$ \\
6. Social interaction & 5.66 & 13.379 & $0.01^{*}$ \\
7. Amenities and facilities & 5.43 & 0.6210 & 0.89 \\
8. Quality of event services & 5.26 & 27.207 & $0.00^{*}$ \\
9. Inviting local community & 5.21 & 23.724 & $0.00^{*}$ \\
10. Combination with other tourist activities & 4.93 & 11.103 & $0.05^{*}$ \\
11. Learn the culture of Limassol/Cyprus & 4.50 & 13.690 & $0.03^{*}$ \\
12. Opportunity to purchase local products/services & 4.43 & 20.448 & $0.00^{*}$ \\
\hline
\end{tabular}

*Significant difference. 
means that both events do not provide opportunities to participants to be engaged in other activities and know better the host destination.

\section{Discussion}

This study shows that the organizers of both events capitalize on the spatial characteristics of Cyprus and its privileged location in the Eastern Mediterranean that have made it an attractive island destination. These characteristics or environmental destination capitals comprise primarily the island's morphology with a combination of long coasts, flat roads, forests, and mountain areas. The Limassol Marathon takes advantage of the city's long coast and flat route, while the Tour of Cyprus starting from Limassol extends to the mountain areas of the island. The small size of Cyprus allows the cyclists to experience most of the island's landscape, while Limassol provides racers with the opportunity to run along its coast in the Mediterranean Sea. Furthermore, the location of Cyprus in Eastern Mediterranean with the temperate weather in early Spring, and its short distance from Europe, Asia, and Africa constitutes an attractive destination for foreign marathon racers and cyclists.

The findings of this study demonstrate that the emergent sport events, which are based on the resort city of Limassol, have identical multiple goals that combine tourism and community development objectives in their mandate. As the events have been initiated solely by volunteering individuals and community groups, in the absence of a centralized government policy, they naturally reflect the sporting community based values of running and cycling. At the same moment, their tourism potential is embedded in the efforts of event organizers who attempt to capitalize on the comparative advantages of Cyprus as a destination in order to attract foreign marathon racers and cyclists. This illustrates the innate tourism orientation of both events, which perhaps led to their inception in the first place, and drives explicitly their development. Nonetheless, given the lack of government support and a comprehensive sport tourism policy, it is questionable whether these single events alone will be able to achieve the range of multiple goals set by their organizers. However, the identical multiple goals of events reveal an untapped potential of attracting different markets with different characteristics and spending patterns, which can produce spill-over community and tourism benefits. This brings forward sport events as an alternative means to address the unsustainable development of Cyprus and improve the quality of life on the island. In this regard, a potential synergy of these currently unrelated events could enhance their capacity and optimize their outcomes.

Apart from the identical multiple goals, a synergy is possible as the event organizers focus on the same event implementation processes and project the same attributes for both events. According to the results of the study, both events face similar problems with the most important being the lack of funding, insufficient know-how, and partial collaboration with a number of agencies or stakeholders. To overcome these difficulties, both event organizers have been relying on the assistance of sponsors, sport organizations, community groups, and participant athletes. This has engendered a community cocreation process capable of conveying the fundamental values of sports and building personal relationships between event organizers and participants, thus creating a unique identity for the events. Further, the Limassol Marathon has achieved to reach varied segments of the local population and spread its message for active living and social solidarity by creating different races in its program, which have attracted increasing participation of the targeted groups.

The perceptions of participants as shown in the survey generally indicate positive views about the staging and organization of the Limassol Marathon but moderate about the Tour of Cyprus. For this reason, the Limassol Marathon has higher intention for repeat visitation/recommendation, while it also appears to have improved the image of Limassol for participants. Nonetheless, participants for both events confirm the appeal of only some proclaimed attributes related to the host destination. These are the natural scenery, the weather, and the connection with the natural environment. Likewise, participants confirm the environmental friendly and active character of the marathon and cycling events. On the other hand, participants show few opportunities to learn about the Cypriot culture, purchase local products, and participate in other tourist activities. This does not confirm the claim of organizers that 
the events project effectively the cultural heritage and hospitality of Cyprus. Similarly, the participants' perceptions do not confirm the claims of organizers that the events provide enough opportunities for social interaction, camaraderie, and relationship building. Another troubling issue in the views of participants is that their experience in both events was neither perceived considerably affective nor thought provoking, because they did not acquire new knowledge or feel inspired with new ideas.

What is then the impact of these new sport events on Cyprus? Although the events have managed to grow in a short period of time, it appears that their actual outcomes and future sustainability are rather limited. This is mainly because of the ad hoc efforts and the lack of collaboration among different event organizers as well as key stakeholders to effectively leverage all its destination capitals. Although Cyprus is a small island developing state, affording thus its embryonic event industry with the same advantages and weaknesses, there is not an operational synergy, hence perpetuating the current fragmentation. As this study demonstrates, the two emergent sport events have the same goals, processes, and attributes, but they do not have a cooperative relationship. The lack of a comprehensive government policy to foster synergies between these events is partly to blame. Because both events started from voluntary initiatives and share the same goals, processes, as well as attributes, synergies can be developed in the emerging small event sector of Cyprus to optimize the use of the island's scarce resources in event hosting and attain intended outcomes.

As it has been shown in the literature, host communities often fail to strategically leverage the benefits of sport events, while those that undertake leveraging initiatives magnify their economic and social outcomes (Chalip \& Leyns, 2002; Kellett et al., 2008). The lack of leverage in the case of Limassol Marathon and the Tour of Cyprus is not surprising, becuase the events are in infancy stage and thus, there is not the necessary know-how and experience. Similarly, the limited collaboration between event organizers and key stakeholders constrains the coordination of any activities that could exploit destination capitals to obtain intended benefits. For example, the reported lack of opportunities by participants to purchase local products or take part in other tourist activities, limit the economic and tourism benefits of both events, while the participants' perceived lack of acquiring new knowledge and ideas or experiencing a heighted sense of community, constrain the social impact of the events. In this regard, the coordinated organization of ancillary events and activities could provide opportunities for the economic and social leverage of both events (O'Brien \& Chalip, 2008).

In doing so, the coordination of event stakeholders is essential. A coordinated events network can enable collaboration in the staging and leveraging of events (Ziakas \& Costa, 2010b). This requires the mobilization of stakeholders and the establishment of interorganizational relationships to support event implementations. Thus, the Limassol Marathon and the Tour of Cyprus, if it is to achieve sustainable outcomes, need first to substantially increase public awareness for their potential contribution to the sustainable development of the island and consequently, garner support from a network of stakeholders and organizations. As the comparative analysis of the events indicates, their existing interrelationships warrant the development of synergies, if appropriate actions are taken. To this end, the Limassol Marathon and the Tour of Cyprus can be synergized by sharing an integrated set of resources and employing joint strategies and tactics. On this basis, the opportunity that needs to be exploited is the addition of other comparable and/ or complementary events, thereby eventually creating the island's event portfolio capable of achieving synergistically multiple social and tourism goals. An event portfolio can become a tool for sustainable multipurpose development (Ziakas \& Costa, 2011b), provided that events functionally and conceptually complement one another and are cross-leveraged to optimize jointly event outcomes (Ziakas, 2013b).

The multifaceted value of event portfolios has been demonstrated within the regional context (Ziakas, 2010, 2013a) capable of fostering community and tourism development (Ziakas \& Costa, 2011a). In the case of small island developing states, event portfolios can be created on the island-wide level by taking advantage of their spatial characteristics. Therefore, the emergence of sport events in Cyprus illustrates the potential to develop in the 
future the whole island's event portfolio. Given the small size of the island, the coordinated hosting of sport events and ancillary activities can spread benefits to peripheral areas (Smith, 2009), engender flow-on tourism (Taks, Chalip, Green, Kesenne, \& Martyn, 2009), and reinforce an attitude change for local people towards norms of active living (Weed, 2012), volunteerism (Nichols \& Ralston, 2012), and sustainability (VanWynsberghe et al., 2012). In this respect, an encouraging finding of the study is the cocreation process in the emergent sport events, which may have been developed out of necessity due to the event organizers' scarce resources, but it can create and maintain stronger relationships with stakeholders, thereby broadening the appeal of events to many people.

In light of the empirical evidence that derived from the study, this research suggests that smallscale sport events constitute a versatile policy tool for small island developing states capable of contributing to their sustainable development. This is mainly because a variety of small-scale sport events can be designed to coincide with the spatial and cultural characteristics of the host island, based on the interconnectedness of destination capitals, while operating within its resource capacity and thus avoid being dependent on foreign capital investment. To fully exploit the potential of smallscale sport events and optimize their outcomes, a comprehensive event policy is required that synergize economic and social leverage. Within the context of an island's portfolio, an array of smallscale events can be cross-leveraged easier to attain and magnify multiple strategic outcomes. From this perspective, small island developing states can employ small-scale sport events to diversify their tourism product and enhance their sustainability by implementing joint strategies and tactics.

\section{Conclusions and Future Research}

The emergence of marathon running and cycling illustrates a small but essential change in the football-dominated sport culture of Cyprus. It represents an effort by local people to employ two sports that have not been popular on the island and engage local support in the subsequent creation of small-scale events. Although these events are by their very nature linked to the tourism industry, the social character of running and cycling helps convey societal messages that can improve the health, environment, and overall quality of life in Cyprus by promoting sport participation and an active lifestyle. However, to facilitate the sustainability of the emerging events and the attainment of intended outcomes, a strategic approach is needed for planning and leveraging these events jointly and in synergy with the island's assets or interconnected destination capitals.

The implications of this study point out to the synergistic value of small-scale sport events and the strategic processes for creating a range of sustainable event outcomes. Specifically, the findings of this study illustrate how the spatial characteristics of small island developing states affect the choice of sport events and their impacts. Most importantly, the comparative examination of two sport events sheds light on their interrelationships and the potential to amplify the value of small-scale events when they are synergized. Within this context, the staging of new events can enable the achievement of multiple purposes such as enhancing local community development, building capacity, and enriching the tourism product. In doing so, it is suggested that the strategic outcomes of different small-scale events can be optimized if they are assembled in a portfolio. This requires the setting up of crossleveraging strategies that exploit the interconnections of destination capitals and different events in order to foster operational and thematic synergies that will magnify their value.

A limitation of the study is the small number of respondents in the survey for both events. More respondents would give a more complete illustration in regards to participants' perceptions of these two events. Another limitation is that while the study explored the perspectives of event organizers and participants, it did not examine the perceptions of attendees, residents, and other stakeholders. As such, future research needs to analyze the perceptions of all the above stakeholders. Similarly, further research should explore the sustainability of small-scale sport events in other island destinations with different characteristics and find out how they affect the processes and outcomes of events. A comparative analysis of sport events (and other event genres) can reveal their interrelationships and pinpoint the strategic means for creating synergies 
and event portfolios. Given the scarce resources of small islands, the process of cocreation should be examined in order to better understand how we can develop value in small-scale sport events. Finally, the links between tourism and community development need to be explored in future research and identify the factors that enable small-scale sport events to achieve economic and social outcomes and contribute to the sustainable development of the host island.

\section{References}

Agrusa, J., Tanner, J., \& Lema, D. (2006). Japanese runners in the Honolulu Marathon and their economic benefits to Hawaii. Tourism Review International, 9(3), 261-270.

Archontides, Y. K. (2007). Review of Cypriot tourism: Through a series of articles, interviews and speeches. Athens, Greece: A. A. Livani [in Greek].

Balduck, A., Maes, M., \& Buelens, M. (2011). The social impact of the Tour de France: Comparisons of residents' pre- and post-event perceptions. European Sport Management Quarterly, 11(2), 91-113.

Bale, J. (2003). Sports geography (2nd ed.). London: Routledge.

Berridge, G. (2012). The promotion of cycling in London: The impact of the 2007 Tour de France Grand Depart on the image and provision of cycling in the capital. Journal of Sport and Tourism, 17(1), 43-61.

Boukas, N., Boustras, G., \& Sinka, A. (2012). Golf tourism in Cyprus. In O. Mufakkir \& P. M. Burns (Eds.), Controversies in tourism (pp. 144-159). Wallingford, UK: CABI.

Boukas, N., \& Ziakas, V. (2013a). Impacts of the global economic crisis on Cyprus tourism and policy responses. International Journal of Tourism Research, 15(4), 329-345.

Boukas, N., \& Ziakas, V. (2013b). Exploring perceptions for Cyprus as a sustainable golf destination: Motivational and attitudinal orientations of golf tourists. International Journal of Sport Management and Marketing, 14(1/4), 39-70.

Boukas, N., Ziakas, V., \& Boustras, G. (2013). Olympic legacy and cultural tourism: Exploring the facets of Athens' Olympic heritage. International Journal of Heritage Studies, 19(2), 203-228.

Brown, G., Chalip, L., Jago, L., \& Mules, T. (2004). Developing brand Australia: Examining the role of events. In N. Morgan, A. Pritchard, \& R. Pride (Eds.), Destination branding: Creating the unique destination proposition (2nd ed.) (pp. 279-305). Oxford, UK: Elsevier Butterworth-Heinemann.

Bryman, A., \& Cramer, D. (2001). Quantitative data Analysis with SPSS, release 10 for Windows: A guide for social scientists. East Sussex, UK: Routledge.
Bull, C. (2006). Racing cyclists as sports tourists: The experiences and behaviours of a case study group of cyclists in East Kent, England. Journal of Sport and Tourism, 11(3/4), 259-274.

Bull, C., \& Lovell, J. (2007). The impact of hosting major sporting events on local residents: An analysis of the views and perceptions of Canterbury residents in relation to the Tour de France 2007. Journal of Sport and Tourism, 12(3/4), 229-248.

Bull, C., \& Weed, M. (1999). Niche markets and small island tourism: The development of sports tourism in Malta. Managing Leisure, 4(3), 142-155.

Burbank, M. J., Andranovich, G., \& Heying, C. H. (2002). Mega-events, urban development and public policy. Review of Policy Research, 19(3), 179-202.

Butler, R. (2008). Islands. In M. Lück (Ed.), Encyclopedia of tourism and recreation in marine environments (p. 254). Wallingford, UK: CABI.

Carlsen, J., \& Butler, R. (2011). Introducing sustainable perspectives of island tourism. In J. Carlsen \& R. Butler (Eds.), Island tourism: Sustainable perspectives (pp. 1-8). Wallingford, UK: CABI.

Carlsen, J., \& Taylor, A. (2003). Mega-events and urban renewal: The case of the Manchester 2002 Commonwealth Games. Event Management, 8(1), 15-22.

Chalip, L. (2004). Beyond impact: A general model for sport event leverage. In B. W. Ritchie \& D. Adair (Eds.), Sport tourism: Interrelationships, impacts and issues (pp. 226252). Clevedon, UK: Channel View.

Chalip, L., \& Costa, C. A. (2005). Sport event tourism and the destination brand: Towards a general theory. Sport in Society, 8(2), 218-237.

Chalip, L., \& Leyns, A. (2002). Local business leveraging of a sport event: Managing an event for economic benefit. Journal of Sport Management, 16(2), 132-158.

Chalip, L., \& McGuirty, J. (2004). Bundling sport events with the host destination. Journal of Sport and Tourism, 9(3), 267-282.

Chalip, L., Green, B. C., \& Hill, B. (2003). Effects of sport event media on destination image and intention to visit. Journal of Sport Management, 17(3), 214-234.

Coghlan, A. (2012). An autoethnographic account of a cycling charity challenge event: Exploring manifest and latent aspects of the experience. Journal of Sport and Tourism, 17(2), 105-124.

Craigwell, R. (2007). Tourism competitiveness in small island developing states. UNU-WIDER, 19, 1-26.

Dansero, E., \& Puttilli, M. (2010). Mega-events tourism legacies: The case of the Torino 2006 Winter Olympic Games - a territorialisation approach. Leisure Studies, 29(3), 321-341.

Decrop, A. (1999). Triangulation in qualitative tourism research. Tourism Management, 20(1), 157-161

Downward, P., Lumsdon, L., \& Weston, R. (2009). Visitor expenditure: The case of cycle recreation and tourism. Journal of Sport and Tourism, 14(1), 25-42.

Essex, S., \& Chalkley, B. (1998). Olympic Games: Catalyst of urban change. Leisure Studies, 17(3), 187-206. 
European Commission. (2010). Sport and physical activity. Brussels, Belgium: Special Eurobarometer 334, Directorate General Education and Culture.

Faulkner, B., Chalip, L., Brown, G., Jago, L., March, R., \& Woodside, A. (2000). Monitoring the tourism impacts of the Sydney 2000 Olympics. Event Management, 6(4), 231-246.

Filo, K. R., Funk, D. C., \& O’Brien, D. (2008). It's really not about the bike: Exploring attraction and attachment to the events of the Lance Armstrong Foundation. Journal of Sport Management, 22(5), 501-525.

Finn, M., Elliot-White, M., \& Walton, M. (2000). Tourism and leisure research methods: Data collection, analysis and interpretation. Essex, UK: Pearson Educated Limited.

Frawley, S., \& Cush, A. (2011). Major sport events and participation legacy: The case of the 2003 Rugby World Cup. Managing Leisure, 16(1), 65-76.

Garcia, B. (2004). Urban regeneration, arts programming and major events: Glasgow 1990, Sydney 2000 and Barcelona 2004. International Journal of Cultural Policy, 10(1), 103-118.

Getz, D. (2012). Event studies: Theory, research and policy for planned events (2nd ed.). London: Routledge.

Gibson, H. J., Kaplanidou, K., \& Kang, S. J. (2012). Smallscale event sport tourism: A case study in sustainable tourism. Sport Management Review, 15(2), 160-170.

Gibson, H. J., Qi, C. X., \& Zhang, J. J. (2008). Destination image and intent to visit China and the 2008 Beijing Olympic Games. Journal of Sport Management, 22(4), 427-450.

Girginov, V., \& Hills, L. (2008). A sustainable sports legacy: Creating a link between the London Olympics and sports participation. International Journal of the History of Sport, 25(14), 2091-2116.

Glaser, B. G., \& Strauss, A. L. (1967). The discovery of grounded theory: Strategies for qualitative research. Chicago, IL: Aldine Publishing.

Grix, J. (2012). "Image" leveraging and sports mega-events: Germany and the 2006 FIFA World Cup. Journal of Sport and Tourism, 17(4), 289-312.

Hampton, M. P., \& Christensen, J. (2007). Competing industries in islands: A new tourism approach. Annals of Tourism Research, 34(4), 998-1020.

Higham, J. (1999). Commentary-Sport as an avenue of tourism development: An analysis of the positive and negative impacts of sport tourism. Current Issues in Tourism, 2(1), 82-90.

Higham, J., \& Hinch, T. (2002). Tourism, sport and seasons: The challenges and potential of overcoming seasonality in the sport and tourism sectors. Tourism Management, 23(2), 175-185.

Higham, J., \& Ritchie, J. R. B. (2001). The evolution of festivals and other events in rural southern New Zealand. Event Management, 7(1), 39-49.

Hiller, H. H. (2006). Post-event outcomes and the postmodern turn: The Olympics and urban transformations. European Sport Management Quarterly, 6(4), 317-332.
Ioannides, D. (1992). Tourism development agents: The Cypriot resort cycle. Annals of Tourism Research, 19(4), 711-731.

Ioannides, D. (2001). The dynamics and effects of tourism evolution in a divided island. In Y. Apostolopoulos, P. Loukissas, \& L. Leontidou (Eds.), Mediterranean tourism: Facets of socioeconomic development and cultural change (pp. 112-128). London: Routledge.

Ioannides, D., \& Holcomb, B. (2001). Raising the stakes: Implications of upmarket tourism policies in Cyprus and Malta. In D. Ioannides, Y. Apostolopoulos, \& S. Sonmez (Eds.), Mediterranean islands and sustainable tourism development: Practices, management, and policies (pp. 234-258). London: Continuum.

Janiskee, R. L., \& Drews, P. L. (1998). Rural festivals and community reimaging. In R. Butler, C. M. Hall, \& J. Jenkins (Eds.), Tourism and recreation in rural areas (pp. 157-175). Chichester, UK: Wiley.

Jones, C. (2005). Major events, networks and regional development. Regional Studies, 39(2), 185-195.

Kaplanidou, K. (2012). The importance of legacy outcomes for Olympic Games four summer host cities residents' quality of life: 1996-2008. European Sport Management Quarterly, 12(4), 397-433.

Kartakoullis, N. L., Kriemadis, T., \& Pouloukas, S. (2009). Cyprus: A football crazy nation? Soccer \& Society, 10(2), 226-244.

Kellett, P., Hede, A. M., \& Chalip, L. (2008). Social policy for sport events: Leveraging (relationships with) teams from other nations for community benefit. European Sport Management Quarterly, 8(2), 101-121.

Kruger, M., \& Saayman, M. (2012). Creating a memorable spectator experience at the Two Oceans Marathon. Journal of Sport and Tourism, 17(1), 63-77.

Lamont, M. (2009). Reinventing the wheel: A definitional discussion of bicycle tourism. Journal of Sport and Tourism, 14(1), 5-23.

Lamont, M., \& McKay, J. (2013). Intimations of postmodernity in sports tourism at the Tour de France. Journal of Sport and Tourism, 17(4), 313-331.

Lewis-Cameron, A., \& Roberts, S. (2010). Small island developing states: Issues and prospects. In A. LewisCameron \& S. Roberts (Eds.), Marketing island destinations: Concepts and cases (pp. 1-8). London: Elsevier.

Lim, C. C., \& Patterson, I. (2008). Sport tourism on the islands: The impact of an international mega golf event. Journal of Sport and Tourism, 13(2), 115-133.

Miles, M., \& Huberman, A. (1994). Qualitative data analysis (2nd ed.). London: Sage.

Misener, L., \& Mason, D. S. (2006). Creating community networks: Can sporting events offer meaningful sources of social capital? Managing Leisure, 11(1), 39-56.

Misener, L., \& Mason, D. S. (2008). Urban regimes and the sporting events agenda: A cross-national comparison of civic development strategies. Journal of Sport Management, 22(5), 603-627.

Misener, L., \& Mason, D. S. (2009). Fostering community development through sporting events strategies: An 
examination of urban regime perceptions. Journal of Sport Management, 23(6), 770-794.

Moscardo, G. (2008). Analyzing the role of festivals and events in regional development. Event Management, 11(1/2), 23-32.

Nichols, G., \& Ralston, R. (2012). Lessons from the volunteering legacy of the 2002 Commonwealth Games. Urban Studies, 49(1), 169-184.

Niles, D., \& Baldacchino, G. (2011). Introduction: On island futures. In D. Niles \& G. Baldacchino (Eds.), Island futures: Conservation and development across the AsiaPacific region (pp. 1-8). New York: Springer.

O'Brien, D. (2006). Event business leveraging: The Sydney 2000 Olympic Games. Annals of Tourism Research, 33(1), 240-261.

O'Brien, D. (2007). Points of leverage: Maximizing host community benefit from a regional surfing festival. European Sport Management Quarterly, 7(2), 141-165.

O'Brien, D., \& Chalip, L. (2008). Sport events and strategic leveraging: Pushing towards the triple bottom line. In A. Woodside \& D. Martin (Eds.), Tourism management: Analysis, behaviour and strategy (pp. 318-338). Wallingford, UK: CABI.

Reid, S. (2008). Identifying social consequences of rural events. Event Management, 11(1/2), 89-98.

Reid, S. (2011). Event stakeholder management: Developing sustainable rural event practices. International Journal of Event and Festival Management, 2(1), 20-36.

Rich, T. S. (2008). Island microstates and political contention: An exploratory analysis of Cape Verde and Comoros. African and Asian Studies, 7(2), 217-233.

Ritchie, B. W. (2004). Exploring small-scale sport event tourism: The case of Rugby Union and the Super 12 competition. In B. W. Ritchie \& D. Adair (Eds.), Sport tourism: Interrelationships, impacts and issues (pp. 135154). Clevedon, UK: Channel View.

Ritchie, B. W. (2005). Small-scale sport event tourism: The changing dynamics of the New Zealand Masters Games. In M. Novelli (Ed.), Niche tourism: Contemporary issues, trends and cases (pp. 157-170). Oxford, UK: Elsevier Butterworth-Heinemann.

Ritchie, B. W., Mosedale, L., \& King, J. (2002). Profiling sport tourists: The case of Super 12 Rugby Union in the Australian Capital Territory (ACT), Australia. Current Issues in Tourism, 5(1), 33-44.

Schulenkorf, N., \& Edwards, D. (2012). Maximizing positive social impacts: Strategies for sustaining and leveraging the benefits of inter-community sport events in divided societies. Journal of Sport Management, 26(5), 379-390.

Schulenkorf, N., Thomson, A., \& Schlenker, K. (2011). Inter-community sport events: Vehicles and catalysts for social capital in divided societies. Event Management, 15(2), 105-119.

Sharpley, R. (2002). Rural tourism and the challenge of tourism diversification: The case of Cyprus. Tourism Management, 23(3), 233-244.

Sharpley, R. (2009). Tourism development and the environment: Beyond sustainability? London: Earthscan.
Shipway, R., \& Jones, I. (2007). Running away from home: Understanding visitor experiences and behaviour at sport tourism events. International Journal of Tourism Research, 9(5), 373-383.

Shipway, R., \& Jones, I. (2008). The Great Suburban Everest: An "insiders" perspective on experiences at the 2007 Flora London Marathon. Journal of Sport and Tourism, 13(1), 61-77.

Smith, A. (2009). Spreading the positive effects of major events to peripheral areas. Journal of Policy Research in Tourism, Leisure and Events, 1(3), 231-246.

Smith, A. (2012). Events and urban regeneration: The strategic use of events to revitalise cities. London: Routledge.

Snelgrove, R., \& Wood, L. (2010). Attracting and leveraging visitors at a charity cycling event. Journal of Sport and Tourism, 15(4), 269-285.

Sugden, J. (2007). Running Havana: Observations on the political economy of sport tourism in Cuba. Leisure Studies, 26(2), 235-251.

Taks, M., Chalip, L., Green, B. C., Kesenne, S., \& Martyn, S. (2009). Factors affecting repeat visitation and flow-on tourism as sources of event strategy sustainability. Journal of Sport and Tourism, 14(2/3), 121-142.

VanWynsberghe, R., Derom, I., \& Maurer, E. (2012). Social leveraging of the 2010 Olympic Games: "Sustainability" in a City of Vancouver initiative. Journal of Policy Research in Tourism, Leisure and Events, 4(2), 185-205.

Veal, A. J., Toohey, K., \& Frawley, S. (2012). The sport participation legacy of the Sydney 2000 Olympic Games and other international sporting events hosted in Australia. Journal of Policy Research in Tourism, Leisure and Events, 4(2), 155-184.

Weed, M. (2012). Towards an interdisciplinary events research agenda across sport, tourism, leisure and health. In S. J. Page \& J. Connell (Eds.), The Routledge handbook of events (pp. 57-72). Abingdon, UK: Routledge.

Weiss, R. S. (1994). Learning from strangers: The art and method of qualitative interview studies. New York: Free Press.

Wicker, P., Hallman, K., \& Zhang, J. J. (2012). What is influencing consumer expenditure and intention to revisit? An investigation of marathon events. Journal of Sport and Tourism, 17(3), 165-182.

Wilkinson, P. F. (1989). Strategies for tourism in island microstates. Annals of Tourism Research, 16(2), 153-177.

Wilson, R. (2006). The economic impact of local sport events: Significant, limited or otherwise? A case study of four swimming events. Managing Leisure, 11(1), 57-70.

Witt, S. F. (1991). Tourism in Cyprus: Balancing the benefits and costs. Tourism Management, 12(1), 37-45.

Yin, R. K. (2009). Case study research: Design and methods (4th ed.). Thousand Oaks, CA: Sage.

Ziakas, V. (2010). Understanding an event portfolio: The uncovering of interrelationships, synergies, and leveraging opportunities. Journal of Policy Research in Tourism, Leisure and Events, 2(2), 144-164. 
Ziakas, V. (2013a). A multi-dimensional investigation of a regional event portfolio: Advancing theory and praxis. Event Management, 17(1), 27-48.

Ziakas, V. (2013b). Event portfolio planning and management: A holistic approach. London: Routledge.

Ziakas, V., \& Boukas, N. (2012). A neglected legacy: Examining the challenges and potential for sport tourism development in post-Olympic Athens. International Journal of Event and Festival Management, 3(3), 292-316.

Ziakas, V., \& Boukas, N. (2013). Extracting meanings of event tourist experiences: A phenomenological exploration of Limassol carnival. Journal of Destination Marketing and Management, 2(2), 94-107.

Ziakas, V., \& Costa, C. A. (2010a). "Between theatre and sport" in a rural event: Evolving unity and community development from the inside-out. Journal of Sport and Tourism, 15(1), 7-26.

Ziakas, V., \& Costa, C. A. (2010b). Explicating inter-organizational linkages of a host community's events network. International Journal of Event and Festival Management, 1(2), 132-147.

Ziakas, V., \& Costa, C. A. (2011a). The use of an event portfolio in regional community and tourism development: Creating synergy between sport and cultural events. Journal of Sport and Tourism, 16(2), 149-175.

Ziakas, V., \& Costa, C. A. (2011b). Event portfolio and multi-purpose development: Establishing the conceptual grounds. Sport Management Review, 14(4), 409-423. 
